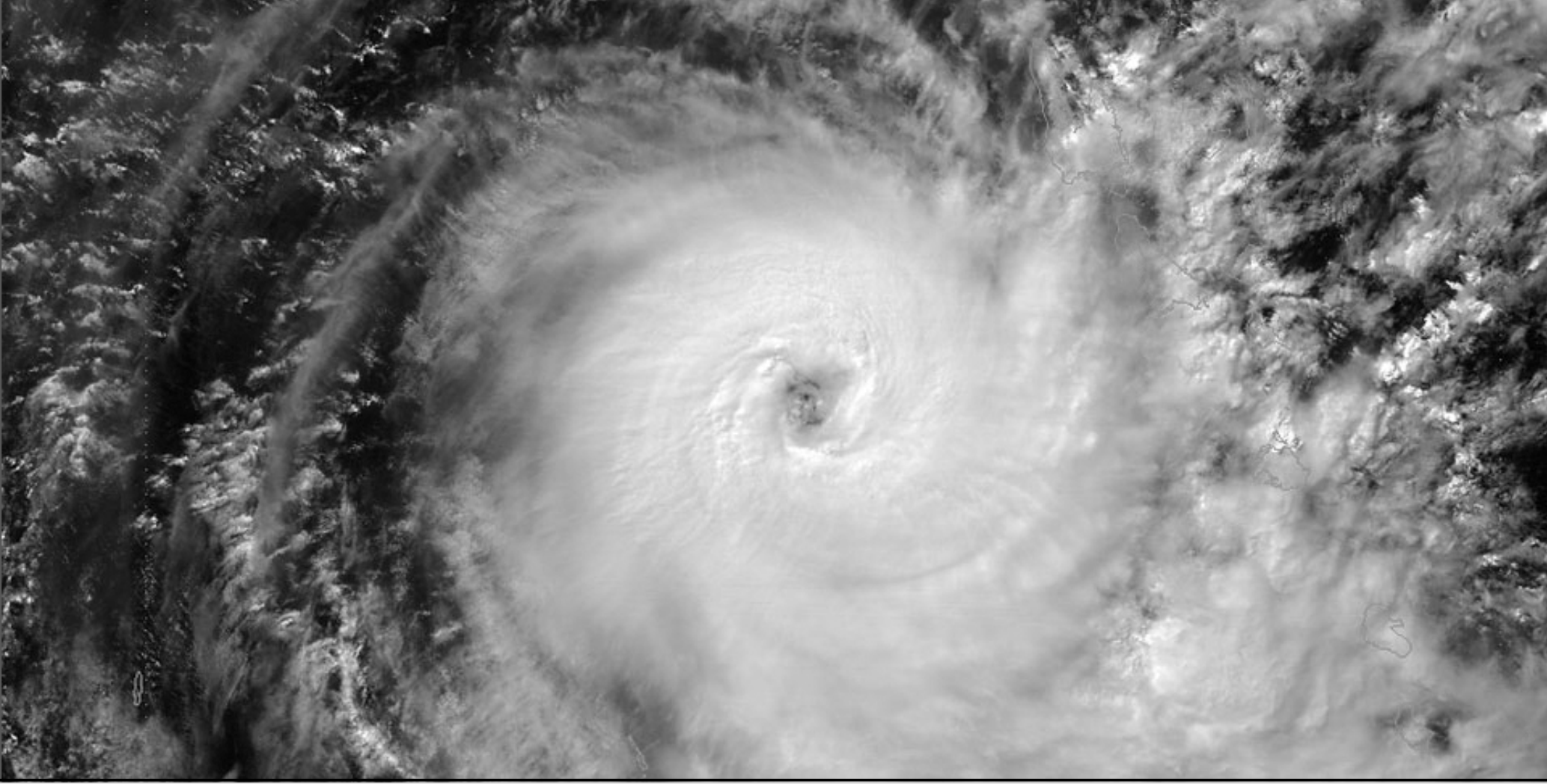

\title{
Satélites meteorológicos
}

Cecilia Marcos Martín

ATAP, Agencia Estatal de Meteorología (AEMET)

The Fifties and Sixties were years of unreal optimism about weather forecasting. Newspapers and magazines were filled with hope for weather science, not just for prediction but for modification and control. Two technologies were maturing together: the digital computer and the space satellite.

Chaos: making a new science - 1987 - JAMES GLEICK

Los satélites se encuentran localizados en una posición privilegiada para poder observar la atmósfera, por lo que las medidas que toman son muy útiles en diferentes ámbitos de la meteorología. En este capítulo se hace una revisión de la evolución de los satélites meteorológicos, poniendo el foco en aquellos que más se usan en la predicción operativa. También se hace un breve resumen sobre las bandas y productos derivados más utilizados de manera operativa, sobre todo en las labores de nowcasting y vigilancia, explicando de manera sucinta su utilización y posibles aplicaciones. De esta manera se pretende proporcionar la información necesaria para un mejor entendimiento de los productos de satélite que puedan aparecer en otros capítulos de este libro.

Palabras clave: satélites meteorológicos, imágenes de satélite, interpretación de imágenes de satélite, productos derivados de las imágenes de satélite, Meteosat, NWCSAF, observación de la atmósfera.

Imagen parte superior: ciclón tropical Donna, que tuvo lugar en el Pacífico Sur el 8 de mayo de 2017. La imagen es de las 3:00 UTC tomada por el satélite Himawari (geostacionario japones) en la banda VIS 0.64. Fuente: EUMETSAT. 


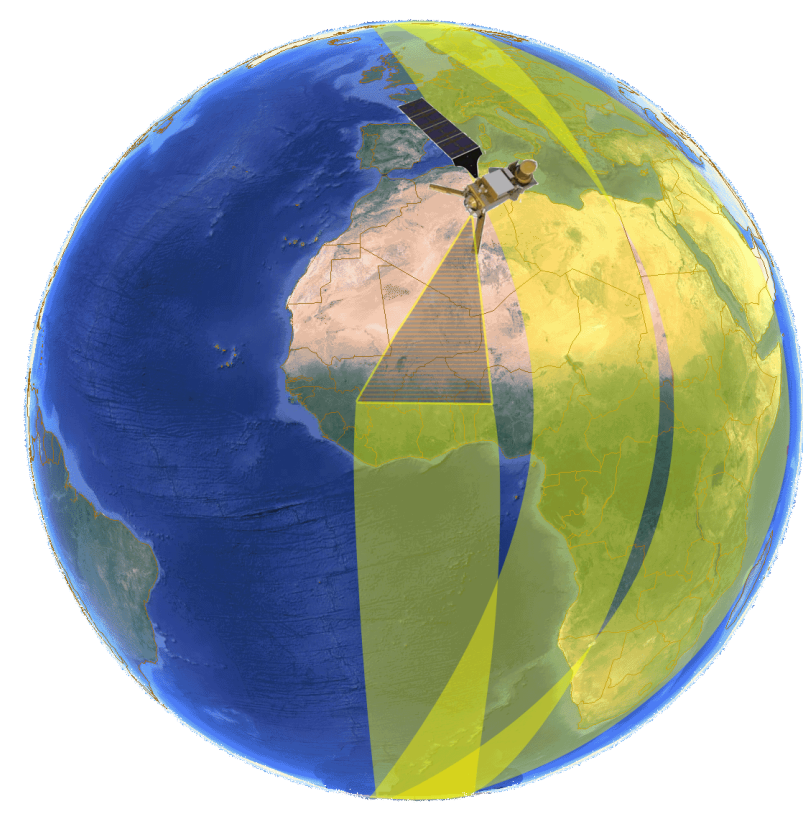

Figura 7.1: Escaneo de un satélite en una órbita polar.

\subsection{Introducción}

Uno de los aspectos más importantes en meteorología es el de las observaciones. Las observaciones son usadas de diferentes maneras: son asimiladas por los modelos numéricos para mejorar las predicciones, usadas en «tiempo real» por los predictores (sec. 4.2.1 en la página 31) para las labores de nowcasting [2], utilizadas para verificar las salidas de los modelos numéricos y de otro tipo de productos, etc. Existen distintos tipos de observaciones. Las observaciones realizadas in situ, por ejemplo por estaciones automáticas o por un observador en una garita, son medidas puntuales de ciertas variables meteorológicas y que, normalmente, se obtienen con alto grado de precisión. Por otro lado están las observaciones realizadas de manera remota, es decir, mediante teledetección. Desde el punto de vista de la localización del instrumento de medición, existen dos tipos de teledetección: la teledetección terrestre, que incluye las redes de rayos y de radares terrestres y la teledetección satelital. Las redes de rayos (sec. 8.10 en la página 114) detectan las descargas eléctricas de los rayos por triangulación, siendo capaces de estimar la localización, tipo e intensidad de las descargas. Los radares terrestres (cap. 8 en la página 103) son aparatos de teledetección activa, que a través de la emisión de un pulso en frecuencia microondas que es capaz de interaccionar con las gotas de agua presentes en la atmósfera, y su posterior recepción, son capaces de estimar la estructura tridimensional de la precipitación y, en el caso de los radares doppler, también el viento radial.
Los satélites meteorológicos tienen una posición privilegiada a la hora de observar la situación meteorológica en su conjunto [5]. Sin embargo, hay que tener siempre presente que, al igual que en el caso del resto de sensores de teledetección, lo que miden es la radiación [7] que llega al sensor. Posteriormente y, dependiendo del tipo de sensor y el rango de frecuencias de la radiación medida, se puede relacionar dicha radiación con otras variables meteorológicas como pueden ser temperatura, viento, precipitación, etc. y, por tanto, hacer una estimación de las mismas [6].

\section{2 Órbitas}

Los instrumentos que más se usan en meteorología van embarcados principalmente en dos tipos de plataformas: geoestacionarias y polares.

Los primeros satélites meteorológicos fueron posicionados en órbitas terrestres bajas, las denominadas LEO (Low Earth Orbit). Durante la primera serie de satélites meteorológicos experimentales lanzados por la National Aeronautics and Space Administration (NASA), los TIROS, se apreciaron las ventajas de la órbita polar, que es un tipo de órbita baja, por lo que los últimos satélites de esta serie fueron posicionados en órbita polar. La órbita polar tiene una inclinación muy cercana a los $90^{\circ}$, con lo que un satélite posicionado en este tipo de órbita pasa muy cerca de los polos y, por tanto, proporciona una buena cobertura de los mismos. Un ejemplo del tipo de escaneo que hace un satélite en una órbita polar se muestra en la Figura 7.1.

Actualmente, la mayor parte de los satélites meteorológicos en órbita baja están posicionados en órbitas polares que, además, son heliosíncronas. Este tipo de órbita se caracteriza por ser una órbita geocéntrica que mantiene fija su orientación relativa al Sol, de manera que el ángulo entre el plano de la órbita y el eje TierraSol se mantiene constante a lo largo del año. Esto tiene una ventaja muy importante para instrumentos que toman medidas en los rangos visible e infrarrojo (IR) del espectro, ya que los puntos localizados a una determinada latitud terrestre son escaneados a la misma hora solar local cada día. Esto hace que el ángulo de iluminación solar sea muy parecido cada vez y por tanto las condiciones de iluminación con las que son tomadas las medidas sobre un punto cada día serán casi las mismas. 


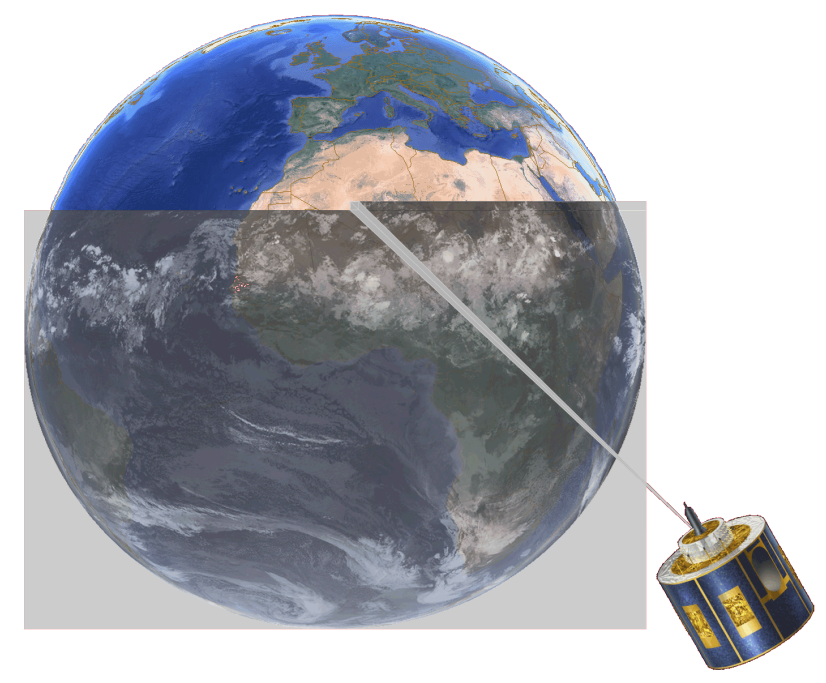

Figura 7.2: Estrategia de escaneo de los satélites geoestacionarios Meteosat de Segunda Generación.

La altura a la que se posicionan típicamente los satélites meteorológicos polares ronda los $890 \mathrm{~km}$. Aunque tardan alrededor de 100 minutos en dar una vuelta completa a la Tierra, la resolución temporal de los mismos (medidas sobre un mismo punto) es de 12 horas. Debido a que estos satélites son de órbita baja, presentan la ventaja de que la resolución espacial con respecto a otro tipo de satélites que vuelan a más altura es mayor. También por este motivo son aptos para llevar a bordo instrumentos de teledetección activa.

Por otra parte y, en general más conocidos, están los satélites posicionados en órbitas geoestacionarias. En el caso de Europa, los satélites que «observan» nuestras longitudes geográficas son los conocidos satélites Meteosat. La órbita geoestacionaria es una órbita circular que tiene una inclinación de cero grados, es decir, que orbita en el plano ecuatorial, siguiendo la dirección de rotación de la Tierra. Otra característica de este tipo de órbita es que posiciona los satélites a altitudes cercanas a los $35790 \mathrm{~km}$, lo que hace que el periodo orbital sea igual al periodo de rotación de la Tierra. De esta forma se consigue que los instrumentos a bordo de estos satélites sean capaces de escanear de manera continua las mismas regiones sobre la superficie terrestre.

Teniendo en cuenta que los satélites geoestacionarios siempre están posicionados en latitud cero grados, los distintos satélites dedicados a cubrir el globo entero se caracterizan por la longitud a la que se encuentran. En el caso de los Meteosat, la longitud es cero grados. Estos satélites tienen una buena cobertura en el ecuador y mala en los polos. También, por estar situados en latitud cero, la resolución espacial es mejor sobre el ecuador, disminuyendo según nos alejamos de este. En la Figura 7.2 se puede ver la estrategia de escaneo del sensor Spinning Enhanced Visible and InfraRed Imager (SEVIRI) embarcado en el satélite geoestacionario Meteosat de Segunda Generación (MSG).

Normalmente, los instrumentos que se embarcan en satélites meteorológicos en órbita geoestacionaria están diseñados para medir radiación global, así como regiones del espectro en los rangos ultravioleta, visible e IR [7]. La principal ventaja de estos instrumentos es que, al permanecer el satélite estático sobre un punto en el ecuador, la resolución temporal viene dada por la velocidad de escaneo del instrumento y la zona que se quiere escanear. Esto permite resoluciones temporales de pocos minutos que, a diferencia de las que proporcionan otro tipo de satélites, permiten la obtención de series de imágenes capaces de mostrar la evolución y el movimiento de los sistemas nubosos con gran detalle.

En algunas ocasiones, bien por la localización de la zona de la que se quieren tomar medidas, bien porque el tipo de medidas que se quieren tomar requieren de una configuración específica, además de los polares y los geoestacionarios, existen satélites meteorológicos posicionados en otro tipo de órbitas. Países que se encuentran en latitudes altas, como es el caso de Rusia y que, por lo tanto, no tienen una buena cobertura de imágenes a partir de satélites geoestacionarios, para la obtención de imágenes con suficiente resolución temporal como para hacer el seguimiento de los sistemas nubosos, han recurrido a la órbita del tipo Molniya. Esta es una órbita elíptica de alta excentricidad, con una inclinación de $63.4^{\circ}$ y un periodo orbital de 12 horas. En este tipo de órbita, el satélite pasa la mayor parte del tiempo recorriendo el apogeo de la órbita, fenómeno conocido como pozo del apogeo, de manera que puede tomar mediciones de forma más o menos continua simulando el funcionamiento de un satélite geoestacionario. Tres satélites posicionados en la misma órbita Molniya permiten una cobertura completa del polo que se observa desde el apogeo de dicha órbita.

Existen dos misiones específicas para el estudio de la precipitación desarrolladas conjuntamente por NASA y Japan Aerospace Exploration Agency (JAXA). La primera denominada TRMM (Tropical Rainfall Measuring Mission) lanzó su satélite en 1997 con un radar a bordo específico para detectar precipitaciones 
intensas tropicales y subtropicales, entre otros instrumentos. Dicho satélite, que proporcionó 17 años de datos, viajaba en una órbita circular no heliosíncrona, con $35^{\circ}$ de inclinación. Tras su lanzamiento se posicionó a una altura de $350 \mathrm{~km}$ y posteriormente, en 2001, se cambió a $403 \mathrm{~km}$, lo que permitía la utilización de un radar activo capaz de generar mapas tridimensionales de precipitación.

En febrero de 2014 se lanzó el satélite principal de la misión GPM (Global Precipitation Measurement), segunda misión también dedicada al estudio de la precipitación. En este caso se trata de una órbita circular no heliosíncrona con $65^{\circ}$ de inclinación y que viaja a $407 \mathrm{~km}$ de altura. Este satélite también lleva a bordo un radar activo de polarización dual capaz de detectar todo tipo de precipitación generando mapas tridimensionales de la misma.

\subsection{Historia}

El primer satélite meteorológico, de nombre TIROS1 (Television Infrared Observational Satellite, Figura 7.3), fue lanzado por Estados Unidos el 1 de abril de 1960 [3]. Las observaciones realizadas por este satélite proporcionaron la primera vista de las nubes asociadas a un sistema meteorológico a gran escala en su conjunto (ver Figura 7.4). Esto supuso una visión de la Tierra desde una perspectiva diferente, siendo la primera vez que se ve una imagen de satélite aplicada a fines meteorológicos tal como las conocemos actualmente.

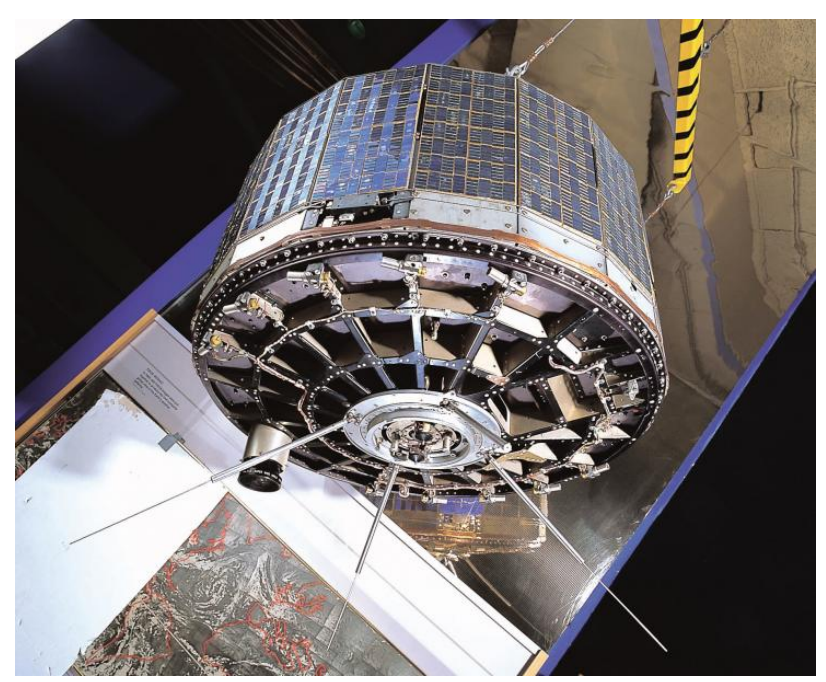

Figura 7.3: Copia del satélite TIROS-1, utilizada para pruebas en tierra y cedida por la NASA al Museo Nacional del Aire y del Espacio en Washington DC, donde se encuentra expuesta. Fuente: Smithsonian National Air and Space Museum.

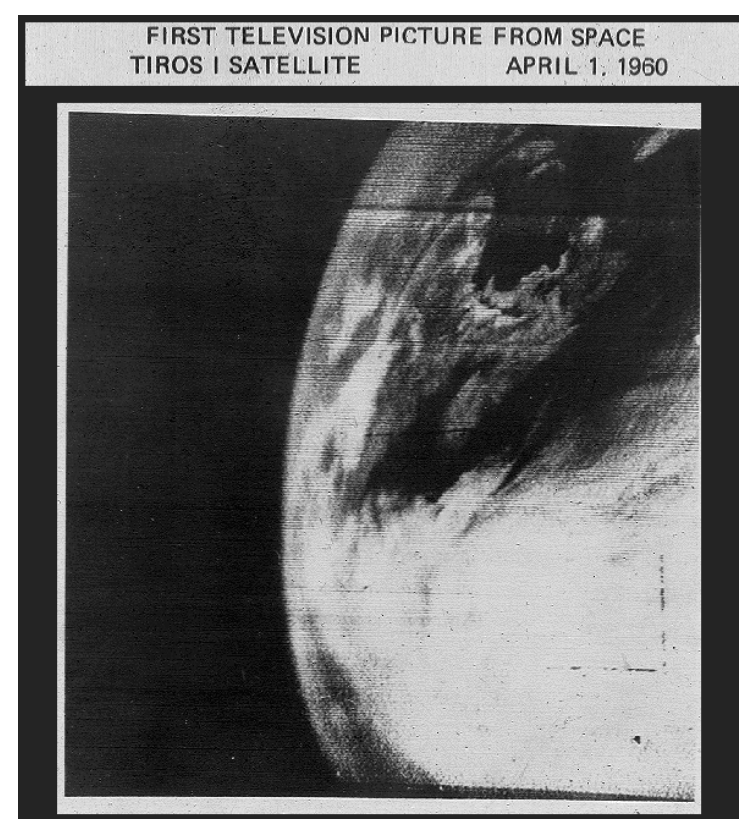

Figura 7.4: Primera imagen televisiva de la Tierra vista desde el espacio tomada desde el satélite TIROS-1. Fuente: NASA

Como precursores de este hito se pueden considerar el lanzamiento del primer cohete de combustible líquido que llevaba un barómetro, un termómetro y una cámara, por parte de Robert Goddard en 1929. Y el lanzamiento exitoso del primer satélite artificial, el Sputnik 1, llevado a cabo por la Unión Soviética el 4 de octubre de 1957.

Debido al éxito y la gran revolución que supusieron las imágenes tomadas en meteorología por el satélite TIROS-1, la NASA lanzó una serie experimental de 10 satélites TIROS que estuvieron funcionando con éxito hasta 1968, siendo el TIROS-9 el primer satélite de la serie en órbita polar. El buen resultado obtenido a través de la serie de satélites TIROS hizo que la ESSA (Environmental Science Services Administration) lanzara una serie de nueve satélites operacionales o TOS (TIROS Operational Satellite) de nombres ESSA-1 a ESSA-9. De manera paralela al programa TOS, la NASA desarrolló otra serie de siete satélites, llamados NIMBUS, dedicados a la investigación científica. Dichos satélites fueron usados de manera muy exitosa como banco de pruebas para el desarrollo de futuros instrumentos de órbita polar, tales como instrumentos de imagen IR, radiómetros microondas y sondeadores en el IR, entre otros. Además, a través de los satélites NIMBUS se alcanzaron un gran número de logros en las áreas de meteorología, oceanografía, geología, hidrología, cartografía y geomorfología. 


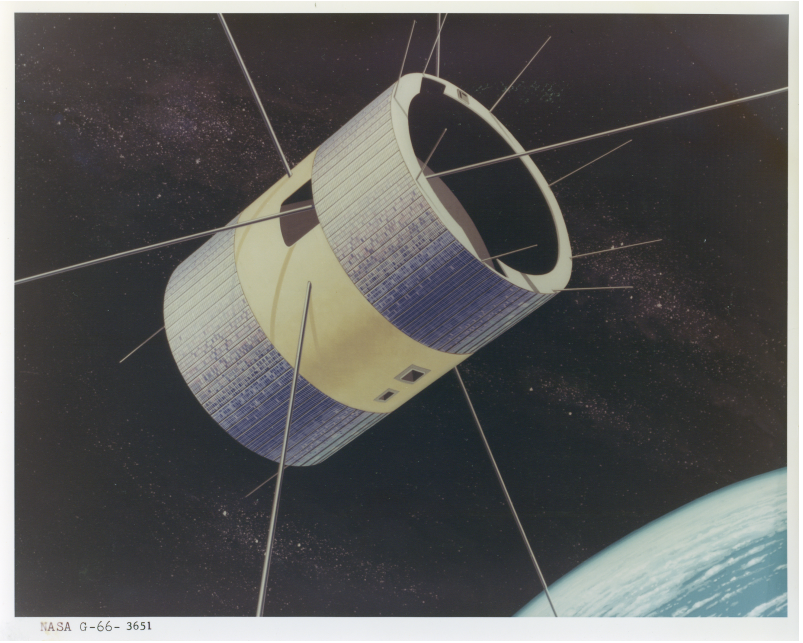

Figura 7.5: Satélite ATS-1. Fuente: NASA.

Con base en toda la experiencia anterior, se consiguió un gran avance con el lanzamiento del satélite NOAA-2 [8] en octubre de 1972, especialmente en el seguimiento operacional de nubes, cambiando la anterior tecnología de cámaras vidicón por radiómetros multiespectrales de alta resolución para ese momento. Otro gran avance tuvo lugar con el primer lanzamiento de la serie TIROS-N en octubre de 1978 y la inclusión del sensor AVHRR (Advance Very High Resolution Radiometer), que por continuidad de series climáticas, todavía se encuentra a bordo de algunos satélites en la actualidad.

El satélite Syncom-3 (Synchronous Communication Satellite) fue el primero en ser posicionado en una órbita geoestacionaria el 19 de agosto de 1964. Dicho satélite fue un satélite experimental de comunicaciones ubicado sobre el ecuador a $180^{\circ}$ de longitud en el océano Pacífico.

Después de haberse demostrado la gran utilidad de las imágenes satelitales para el desarrollo de la meteorología y gracias a los esfuerzos de Verner Suomi y Homer Newell, el satélite ATS-1 (Applications Technology Satellite, Figura 7.5) llevó a bordo una cámara de escaneado giratorio que permitió obtener imágenes en el visible del disco entero cada 20 minutos (Figura 7.6). El ATS-1, que en un principio fue concebido como un satélite de comunicaciones, se convirtió también en el primer satélite en órbita geoestacionaria dedicado a la observación de la Tierra. Dicho satélite fue puesto en órbita el 6 de diciembre de 1966 permitiendo observar, por primera vez en la historia, el movimiento de los sistemas nubosos gracias a una secuencia de imágenes. Este hito supuso un gran avance en el pronóstico del tiempo.
Hubo una serie de seis satélites ATS que fueron lanzados entre 1966 y 1974, siendo el ATS-3 el primero en ser capaz de tomar una imagen a color de la Tierra.

Vista la gran utilidad que en meteorología tuvieron las imágenes tomadas por los satélites de la serie ATS, la NASA desarrolló un prototipo de satélite geoestacionario operacional, el SMS (Synchronous Meteorological Satellite). Este tipo de satélite se generó por duplicado. El SMS-1 se lanzó en mayo de 1974 y el SMS-2 en febrero de 1975, posicionándose en las longitudes $75 \mathrm{~W}$ y $135 \mathrm{~W}$, con el objetivo de cubrir todo el continente americano y el océano Pacífico. Estos satélites llevaron a bordo un radiómetro multiespectral en los rangos visible e IR del espectro con resoluciones espaciales de $1 \mathrm{~km}$ y $7 \mathrm{~km}$ respectivamente en cada rango.

Dos años después, en 1977, la Agencia Espacial Europea lanzó el primer satélite de la serie Meteosat de primera generación (Figura 7.7 en la página siguiente), que incluía siete satélites. El radiómetro incluido en esta serie, el MVIRI (Synchronous Meteorological Satellite), disponía de tres canales, uno en el visible con una resolución de 2,5 km y dos en el IR, con resolución $5 \mathrm{~km}$. El principal avance que supuso este satélite fue el hecho de que una de las bandas del IR está situada en una región de absorción de vapor de agua del espectro. Esto produjo una visión diferente de los sistemas meteorológicos a gran escala proporcionando información muy valiosa sobre humedad en la troposfera alta y sobre la circulación a escala sinóptica.

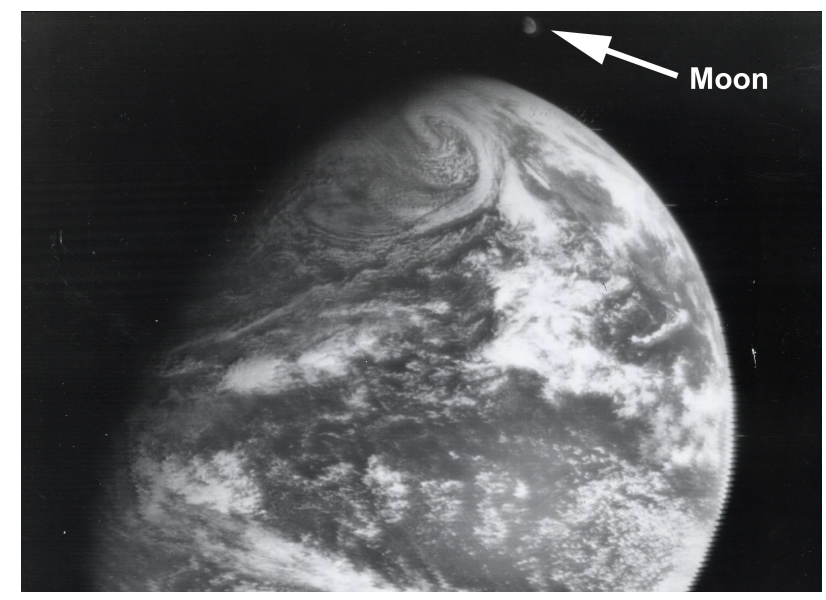

Figura 7.6: Imagen tomada por el satélite ATS-1 en la que por primera vez se obtiene una vista conjunta de la Tierra y la Luna. 


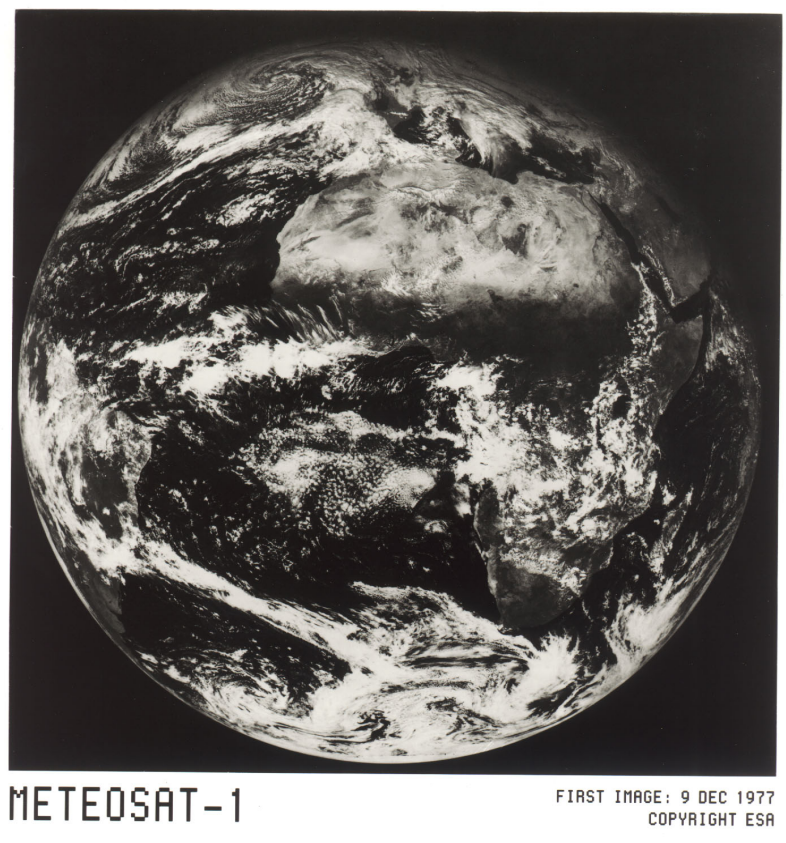

Figura 7.7: Primera imagen tomada por el satélite Meteosat-1. ESA.

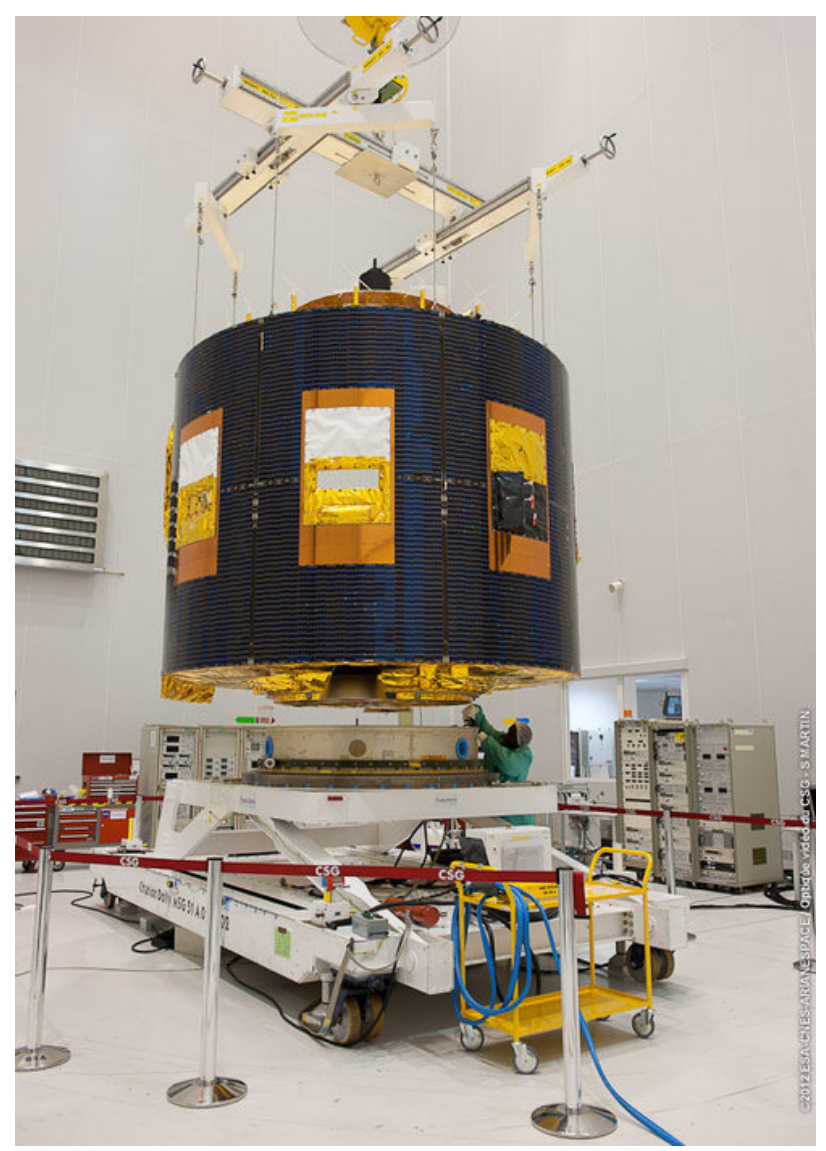

Figura 7.8: Satélite MSG-3 antes de ser puesto en órbita. Fuente: ESA.
Actualmente se encuentra posicionado en la longitud $0^{\circ}$, dando cobertura a Europa y África, el satélite Meteosat-11, perteneciente a la serie MSG (Figura 7.8). Estos llevan a bordo dos instrumentos. GERB (Geostationary Earth Radiation Budget) es un radiómetro con dos canales de banda ancha, en los rangos visibles e IR del espectro, que sirve para calcular la radiación térmica [7] emitida por la Tierra en un rango espectral entre 4.0 y $30 \mu \mathrm{m}$. SEVIRI es el instrumento más utilizado de manera operacional. Este radiómetro proporciona imágenes del disco completo cada $15 \mathrm{mi}$ nutos en 12 bandas en las regiones visible e IR del espectro.

\subsection{Uso operativo de las imáge- nes de satélite}

Como se menciona en el anterior apartado, debido a su alta resolución temporal por estar embarcado a bordo de un satélite geostacionario, las imágenes que más se usan de manera operativa son las tomadas por el sensor SEVIRI. Las 12 bandas de que dispone este sensor se distribuyen en 11 bandas con $3 \mathrm{~km}$ de resolución horizontal en nadir que cubren una región del espectro entre 0.5 y $14.4 \mu \mathrm{m}$ y una banda visible con una resolución de $1 \mathrm{~km}$ en nadir (HRVIS) con un rango de 0.5 a $0.9 \mu \mathrm{m}$.

\subsubsection{Bandas en el visible}

Todas las bandas situadas en el rango del visible detectan albedos, tratándose en este caso de radiación emitida por el sol y reflejada por la superficie terrestre o los topes nubosos [1]. Son bandas ventana, es decir, se ven poco o nada afectadas por absorciones de gases presentes en la atmósfera (sec. 6.1 en la página 68). En cuanto a su interpretación, en ausencia de realces se presentan en tonos de gris representando los distintos tonos el albedo de la superficie y de los topes nubosos, siendo las zonas con mayor albedo las que se ven más claras. La mayor desventaja de las bandas que toman medidas en el visible es que no disponen de información en ausencia de radiación solar.

La banda del visible más utilizada es la HRVIS o visible de alta resolución. Debido precisamente a esa mejor resolución espacial permite la detección de procesos subsinópticos. 


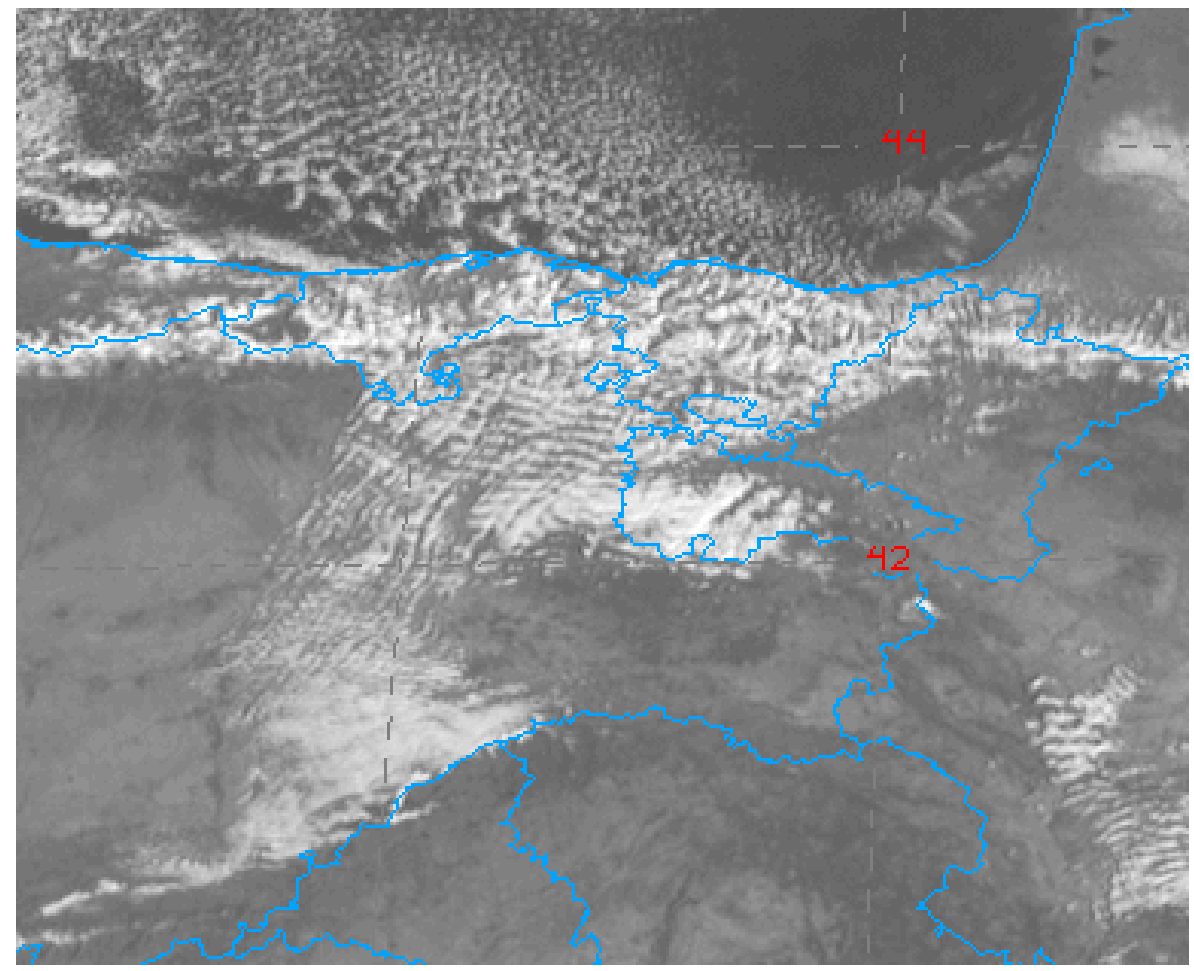

Figura 7.9: Ondas a sotavento en el Cantábrico oriental el 22-02-2018 a las 10:00 UTC vistas en una imagen HRVIS.

Utilizando esta banda podemos apreciar la estructura de los topes nubosos, llegando a distinguirse los topes traspasantes (también conocidos como overshooting tops) de las nubes convectivas, que nos proporcionan una idea de la intensidad de las corrientes verticales que están teniendo lugar dentro de la nube. También se pueden ver bien estructuras nubosas relacionadas con la orografía como las ondas a sotavento (sec. 4.3.2 en la página 39). La Figura 7.9 muestra un ejemplo de este tipo de nubosidad provocada por un flujo del norte que atraviesa el este de la cordillera Cantábrica y los montes Vascos.

Otra utilidad de las imágenes HRVIS es la detección y seguimiento de nieblas durante el día. También son útiles para detectar las primeras formaciones nubosas en entornos preconvectivos.

De las bandas con resolución $3 \mathrm{~km}$, hay dos bandas en el rango del visible, la VIS 0.6 $(0.56-0.71 \mu \mathrm{m})$ y la VIS $0.8(0.74-0.88 \mu \mathrm{m})$. Al igual que la HRVIS, son bandas que permiten el seguimiento de los sistemas nubosos durante el día y proporcionan información sobre el espesor óptico de las nubes. Las nubes más espesas, con mayor desarrollo vertical, reflejan más radiación y, por lo tanto, se ven en colores más claros. A través de las bandas en el visible se pueden clasificar los distintos tipos de nubes atendiendo a su estructura horizontal vista desde el satélite. Las nubes convectivas, con gran desarrollo vertical y poca extensión horizontal, son las más brillantes. Las nubes estratiformes, con gran extensión horizontal, aunque también se ven en tonos claros, son menos brillantes que las convectivas. Los cirros, dependiendo de su espesor, se ven en tonos más o menos oscuros, ya que dejan pasar la mayor parte de la radiación reflejando solo una pequeña parte de ella.

Estas bandas también son utilizadas para la detección de calimas y nubes de humo. Las partículas de esos tamaños producen dispersión de Mie de la radiación en las longitudes de onda del visible, que se caracteriza por un aumento de la dispersión hacia delante, tanto mayor cuanto menor es el ángulo de incidencia de los rayos solares.

La principal diferencia entre ambas bandas en el visible se encuentra en la diferente manera que tienen de reflejar los tipos de superficie. En concreto, la banda VIS 0.8 es sensible a los distintos tipos de vegetación, siendo muy útil para calcular índices de vegetación.

Otra aplicación de las bandas en el visible es que, bajo ciertos ángulos entre el sol y el satélite, las superficies de agua producen reflejo especular (también conocido como sun glint). Cuanto más en calma está el agua, mayor es el albedo. Un mar agitado con muchas olas tiene un albedo más bajo. Teniendo en cuenta que el viento influye en el estado de las aguas, el reflejo especular proporciona información sobre el viento en superficie. 


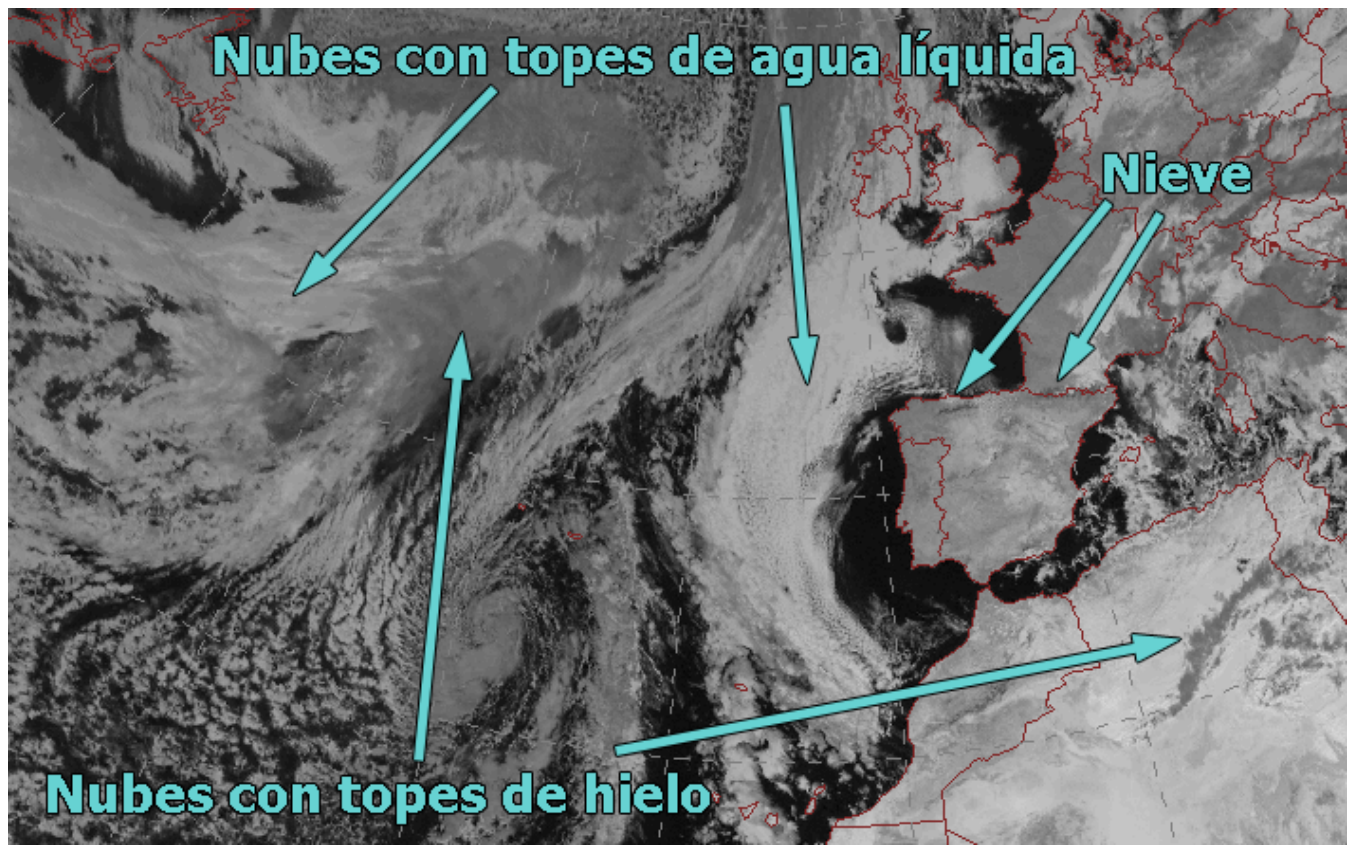

Figura 7.10: Banda NIR 1.6 en 22-02-2018 a las 12:00 UTC en la que se muestra cómo se ven las nubes con topes de agua líquida, de hielo y la nieve.

\subsubsection{Bandas ventana en el IR cercano y en el IR térmico}

Las bandas en el IR cercano tienen enorme utilidad porque contienen, entre otras cosas, información sobre las propiedades microfísicas de los topes nubosos [8]. SEVIRI tiene una banda localizada dentro de este rango del espectro, la NIR 1.6 (1.50-1.78 $\mu \mathrm{m})$. Esta es una banda puramente solar, como lo son las bandas en el rango del visible, por lo tanto también detecta albedos. La principal característica de esta banda es que es sensible a la fase de los topes nubosos, permitiendo también la detección de nieve. En este rango del espectro las partículas de agua líquida reflejan de manera mucho más eficiente la radiación que los cristales de hielo, de modo que las nubes con topes de agua líquida se ven en tonos gris claro mientras que las nubes con topes nubosos en fase hielo y la nieve, se ven en tonos gris oscuro. Podemos ver un ejemplo en la Figura 7.10.

Las bandas en el IR térmico principalmente proporcionan información sobre la temperatura de la superficie y los topes nubosos. En ausencia de realces, al igual que en el caso de las bandas solares, las imágenes se presentan en tonos de gris. En este caso, radiancias más altas, que representan temperaturas de brillo mayores, se presentan en tonos más oscuros. Por el contrario, las superficies frías se ven en tonos gris claro en estas bandas. Esta información sobre la temperatura de los topes nubosos está relacionada con la altura de los mismos. Nubes con topes fríos se encuentran a alturas mayores que nubes con topes más cálidos.

La banda IR $3.9(3.48-4.36 \mu \mathrm{m})$ es una banda mixta. Por la noche es una banda IR térmica que recibe la energía emitida por la superficie terrestre y las nubes. Por el día, además de la parte IR térmica recibe el albedo de las superficies. Esta banda tiene multitud de aplicaciones que en algunos casos dependen del momento del día. Por la noche, al ser un canal IR térmico, sirve para estimar la temperatura de la superficie y para detectar islas de calor urbano. Por el día, debido a la contribución solar, se obtiene información sobre la fase de los topes nubosos y el tamaño de las partículas que forman dichos topes, permitiendo además hacer una buena discriminación de las nubes multicapa. Nubes en capas bajas de la atmósfera, con temperaturas cálidas y formadas por gotas de agua líquida, que reflejan de manera eficiente la energía, se ven en tonos oscuros. Por el contrario, las nubes altas, frías, formadas por cristales de hielo, se ven en tonos claros. Además, debido a que las partículas pequeñas en esta banda reflejan mejor la radiación que les llega que las partículas más grandes, se ven en tono más oscuros. Esto permite el estudio de las estructuras de los topes nubosos atendiendo al tamaño de las partículas que lo forman. Debido a que la banda IR 3.9 tiene una respuesta subpixel muy alta, esta sirve para la detección de incendios, tanto de día como de noche. 


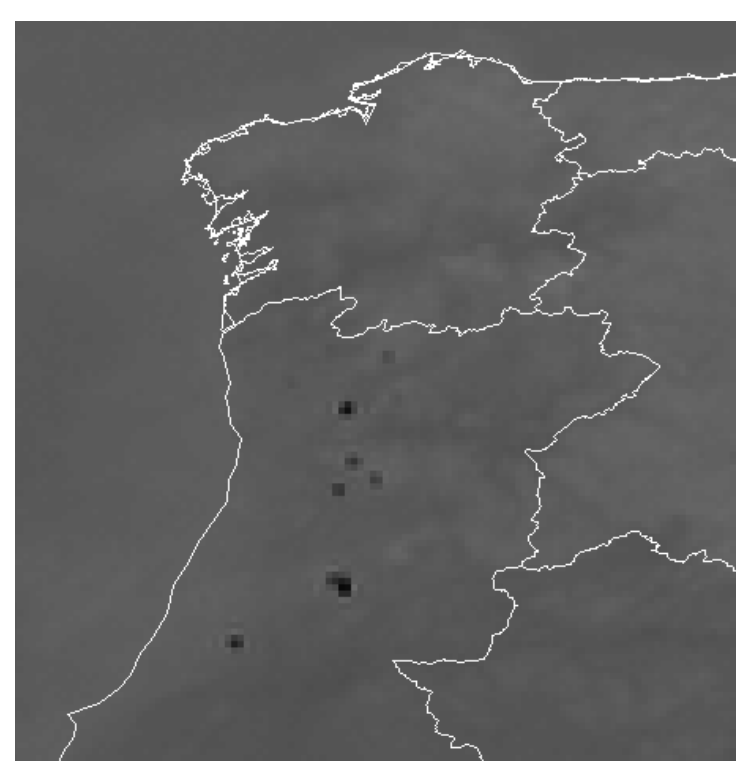

Figura 7.11: Incendios en Portugal el 08-10-2017 a las 18:00 UTC vistos por la banda IR 3.9.

Incluso aunque el incendio no cubra por completo el pixel, la radiancia medida en esta banda aumenta considerablemente cuando existen focos de calor intenso. La Figura 7.11 muestra un ejemplo de incendios en Portugal vistos a través de la banda IR 3.9.

Otras aplicaciones de la banda IR 3.9 válidas en cualquier momento del día son la detección de cirros finos, y de nieblas y nubes bajas. Para ello se usan diferencias con otras bandas.

Existen otras tres bandas ventana en el IR térmico. Son las IR $8.7(8.30-9.10 \mu \mathrm{m})$, IR $10.8(9.80-11.80 \mu \mathrm{m}) \mathrm{e}$ IR $12.0(11.0-13.0 \mu \mathrm{m})$. Aunque todas ellas son bandas térmicas que proporcionan información sobre la temperatura de las superficies, y todas ellas sirven para el estudio y seguimiento de los sistemas nubosos, cada una de ellas tiene sus peculiaridades. Las distintas bandas ventana, en las que la atmósfera es trasparente a la radiación, pueden aun así contener pequeñas líneas de absorción que las proveen de ciertas características y las diferencian unas de otras.

La banda más usada de manera operativa es la IR 10.8. Esta es la banda más limpia, es decir, la menos afectada por pequeñas absorciones. A través de esta banda podemos detectar estructuras atmosféricas a escala sinóptica como pueden frentes, ejes del chorro, dorsales, vaguadas... a través de la configuración de nubes que nos encontremos y estudiar sistemas convectivos mesoescalares a través de la forma y temperatura de los topes nubosos. Esta banda es la que se usa operativamente para hacer las guías técnicas de diagnóstico de niveles bajos en el Centro Nacional de Predicción (CNP) de la Agencia Estatal de Meteorología (AEMET). La Figura 7.12 en la página siguiente muestra un ejemplo de una de estas guías dibujada sobre una imagen de la banda IR 10.8, en la que se ve la borrasca Emma al este de la Península, sobre el Atlántico, con la nubosidad típica de un sistema de bajas presiones con sus frentes asociados.

La banda IR 10.8 también es utilizada en las labores de nowcasting [2] por su gran utilidad en el seguimiento de los sistemas convectivos. Su utilidad viene sobretodo en el seguimiento de los mismos dado que las estructuras típicas de este tipo de sistemas son fácilmente detectables en esta banda. Las temperaturas de los topes nubosos aportan una información muy útil sobre el estado de los mismos. Los topes traspasantes también son detectables en esta banda ya que, al atravesar o deformar las corrientes verticales la inversión de las capas estables presentes en niveles más altos, la temperatura en esos puntos aumenta dando lugar a estructuras de anillos fríos. Para una mejor discriminación de las estructuras de los topes nubosos en cuanto a su temperatura, se suelen aplicar realces de color a esta banda. Estos realces permiten estudiar anillos fríos, y estructuras en forma de U y V, típicas de sistemas convectivos severos con fuerte cizalladura del viento en capas altas de la atmósfera.

La banda IR 10.8, por ser la más limpia en cuanto absorciones, es la que se usa típicamente para hacer diferencias con otras bandas. Por ejemplo se usa junto con la banda IR 3.9 para la detección de nieblas y nubes bajas. Esta detección se basa en que la diferencia IR3.9 - IR10.8 es negativa por la noche debido a que la emisividad de las nubes de agua en niveles bajos es menor en el IR 3.9 que en el IR 10.8. En cambio, de día, la radiación solar reflejada por la banda IR 3.9 por parte de las gotas de agua líquida de la nube hace que dicha diferencia sea positiva. Este método no es válido durante el amanecer y el anochecer.

Usar conjuntamente las bandas IR 3.9 e IR 10.8 sirve para la detección de nubes de agua subfundida. La banda IR 3.9 de día y la diferencia entre ambas bandas por la noche, sirve para detectar la fase. Con la banda IR 10.8 se hace una estimación de la temperatura de la nube. 


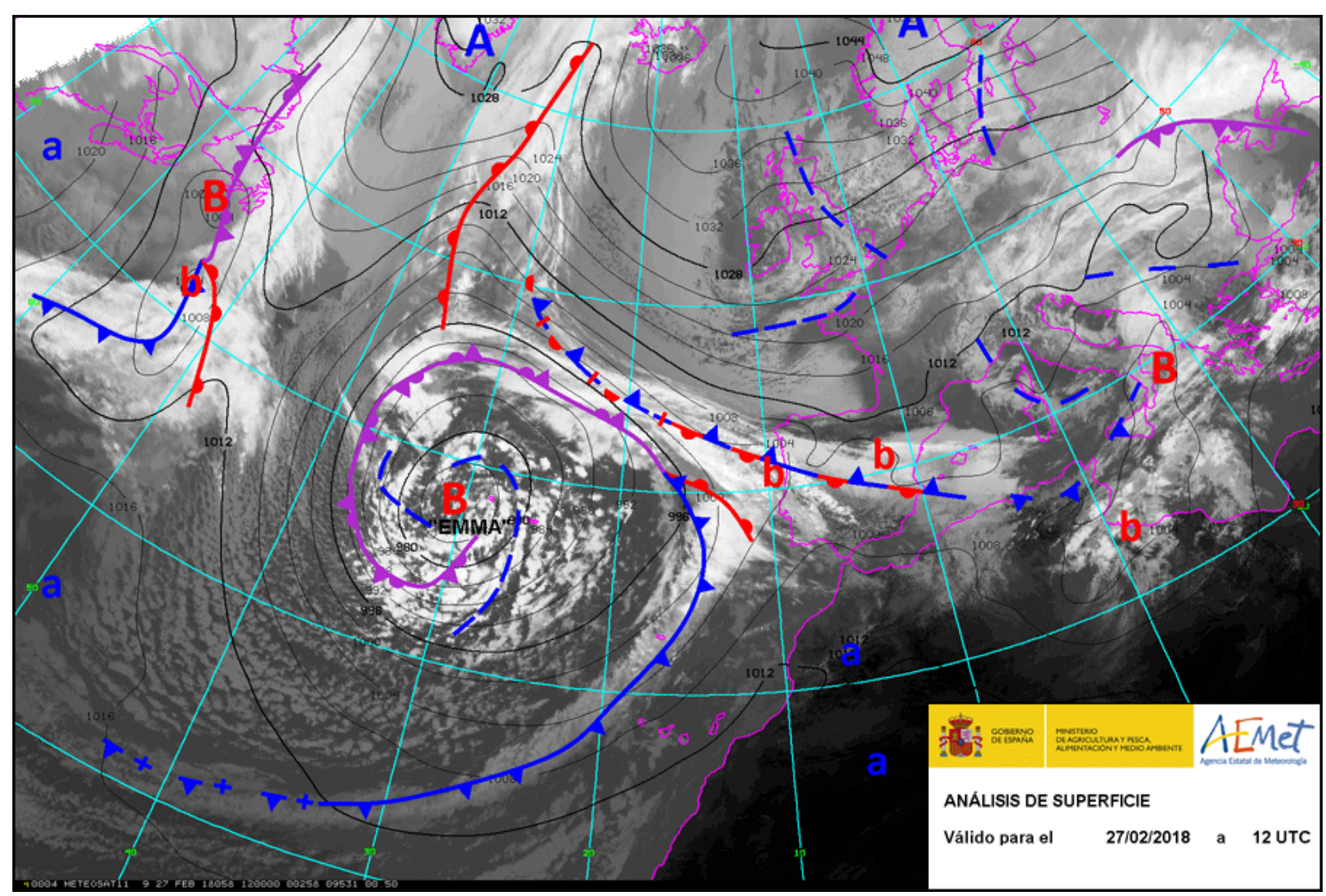

Figura 7.12: Guía técnica de diagnóstico de niveles bajos para el día 27-02-2018 a las 12:00 UTC sobre imagen IR 10.8 .

Debido la diferencia en la absorción de la radiación por parte de las partículas de hielo que forman los cirros finos en las diferentes bandas del IR térmico, las diferencias entre las mismas sirven para detectar este tipo de nubes.

\subsubsection{Bandas de absorción en el IR térmi- co}

Existen cuatro bandas de absorción en el IR térmico. La banda IR 9.7 (9.38-9.94 $\mu \mathrm{m})$ es la de absorción de ozono. Se ve afectada por la absorción de ozono sobretodo en la troposfera alta. En esta banda podemos detectar dobleces de la tropopausa con franjas blancas que representan altas concentraciones de ozono. Normalmente, en estos dobleces de la tropopausa hay una cizalladura vertical del chorro combinada con una convergencia ageostrófica de masas de aire polares, subtropicales y estratosféricas. Estos dobleces marcan el cambio en la altura de la tropopausa y se caracterizan por la ocurrencia de fuerte turbulencia. La banda IR 9.7 también sirve para la detección de vientos en la baja estratosfera [4].

La banda IR 13.4 (12.40-14.40 $\mu \mathrm{m})$ es una banda de absorción de $\mathrm{CO}_{2}$. Sirve para calcular perfiles de tem- peratura, índices de inestabilidad y vientos a través de productos derivados.

Las bandas con absorción más fuerte y más usadas de manera operativa, son las de vapor de agua. Hay dos: la WV 6.2 (5.35-7.15 $\mu \mathrm{m})$ y la WV 7.3 (6.85-7.85 $\mu \mathrm{m})$. Ambas bandas caen dentro de una región del espectro electromagnético de absorción de vapor de agua que está entre los 5 y $8 \mu \mathrm{m}$. La banda WV 6.2 está localizada en el centro de dicha región de absorción, mientras que la banda WV 7.3 se encuentra situada en un borde. El resultado de esto es que la radiación emitida por la superficie en la banda WV 6.2 es absorbida de manera más intensa que la situada en la banda WV 7.3. Es decir, la banda WV 6.2 tiene un poder de absorción mayor. Lo que ocurre con estas bandas es que, en presencia de humedad, toda la radiación emitida por la superficie es absorbida por el vapor de agua antes de llegar al satélite. Al absorber esta energía, las moléculas de vapor de agua modifican su temperatura y reemiten energía dependiendo de dicha temperatura según la Ley de PLANCK (sec. 6.1 en la página 68). Por este motivo, las imágenes que obtenemos a través de estas bandas de absorción, nos muestran información directa sobre la presencia de vapor de agua en la atmósfera y sobre su movimiento. 
Standard Mid-Latitude Summer Nadir

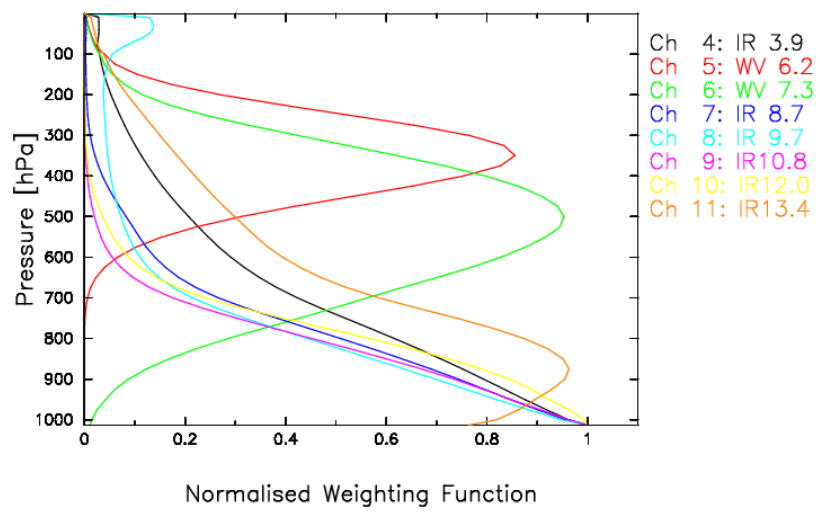

Figura 7.13: Funciones de peso de las bandas del sensor SEVIRI. Fuente: EUMETSAT.

Esto es muy interesante ya que, de esta manera, estas bandas nos permiten «ver» la atmósfera y su evolución de manera bastante clara. Además del diferente poder de absorción, las dos bandas de vapor de agua difieren en la localización del vapor de agua que afecta a cada una de ellas.

Este comportamiento se ve a través de las funciones de peso, que proporcionan información sobre la variación de la transmitancia con la presión para cada longitud de onda, es decir, nos informan acerca de dónde proviene la mayor parte de la radiación que llega al sensor debido a la contribución de la atmósfera. En la Figura 7.13 se pueden ver las funciones de peso para cada una de las bandas del sensor SEVIRI. En concreto estas nos muestran dichas funciones calculadas para unas condiciones típicas del verano de latitudes medias, pero hay que tener en cuenta que varían ligeramente de forma y posición dependiendo de las condiciones de temperatura y humedad de la atmósfera. En rojo vemos la función de peso de la banda WV 6.2 y vemos como la mayor parte de la contribución de esta banda viene de niveles altos de la troposfera. En cambio, la función de peso de la banda WV 7.3 (en verde), es más ancha, llegando incluso a tener una pequeña contribución de la superficie. Y la mayor contribución en esta banda proviene del vapor de agua presente en niveles medios de la troposfera. Por ello, en condiciones muy secas en niveles medios es posible llegar a ver características de la superficie tales como montañas, zonas nevadas, ondas orográfi- cas, etc.

$\mathrm{Al}$ igual que en el resto de bandas, las imágenes obtenidas a través de las bandas de vapor de agua típicamente se presentan en tonos en gris. $\mathrm{Y}$ al ser bandas en el IR térmico, estas imágenes también son mapas térmicos en los que los tonos claros significan temperaturas frías y los oscuros, temperaturas más altas. Pero debido a que nos encontramos ante bandas de absorción, la interpretación es la siguiente:

- Tonos blancos o gris muy claro: nos encontramos ante nubes. La radiación que proviene de la superficie y las capas más bajas de la atmósfera es totalmente interceptada y vemos los topes nubosos más fríos.

- Tonos gris oscuro a negro: la atmósfera está seca en estas zonas (recordar que en cada banda la contribución viene de una capa de la atmósfera). La radiación emitida en la superficie y en capas más bajas de la atmósfera, que son más cálidas, llega al satélite.

- Diferentes tonalidades de gris: proporcionan información sobre la concentración de vapor de agua en distintas capas de la atmósfera, dependiendo de la banda en cuestión.

La gran ventaja de estas bandas es que proporcionan continuidad visual en las estructuras dinámicas de la atmósfera, ya que, no solo permiten ver las nubes, sino también el vapor de agua. La banda WV 7.3, por tanto, proporciona información sobre la distribución y contenido de humedad en capas medias de la troposfera. Por su parte, la banda WV 6.2, una de las bandas más utilizadas de manera operativa, proporciona información sobre la distribución y contenido de humedad en capas altas de la troposfera. Lo que estamos viendo cuando miramos una imagen de la banda WV 6.2 es una imagen tridimensional de la isosuperficie de $1 \mathrm{~mm}$ de vapor de agua que llega al satélite. Como el vapor de agua está distribuido de diferente manera no solo en la horizontal, sino en la vertical a lo largo de la troposfera, con las bandas de vapor de agua se generan imágenes que muestran superficies tridimensionales. Las áreas oscuras, que se refieren a zonas secas, muestran la radiación que proviene de zonas más bajas en la atmósfera y por tanto más cálidas. 


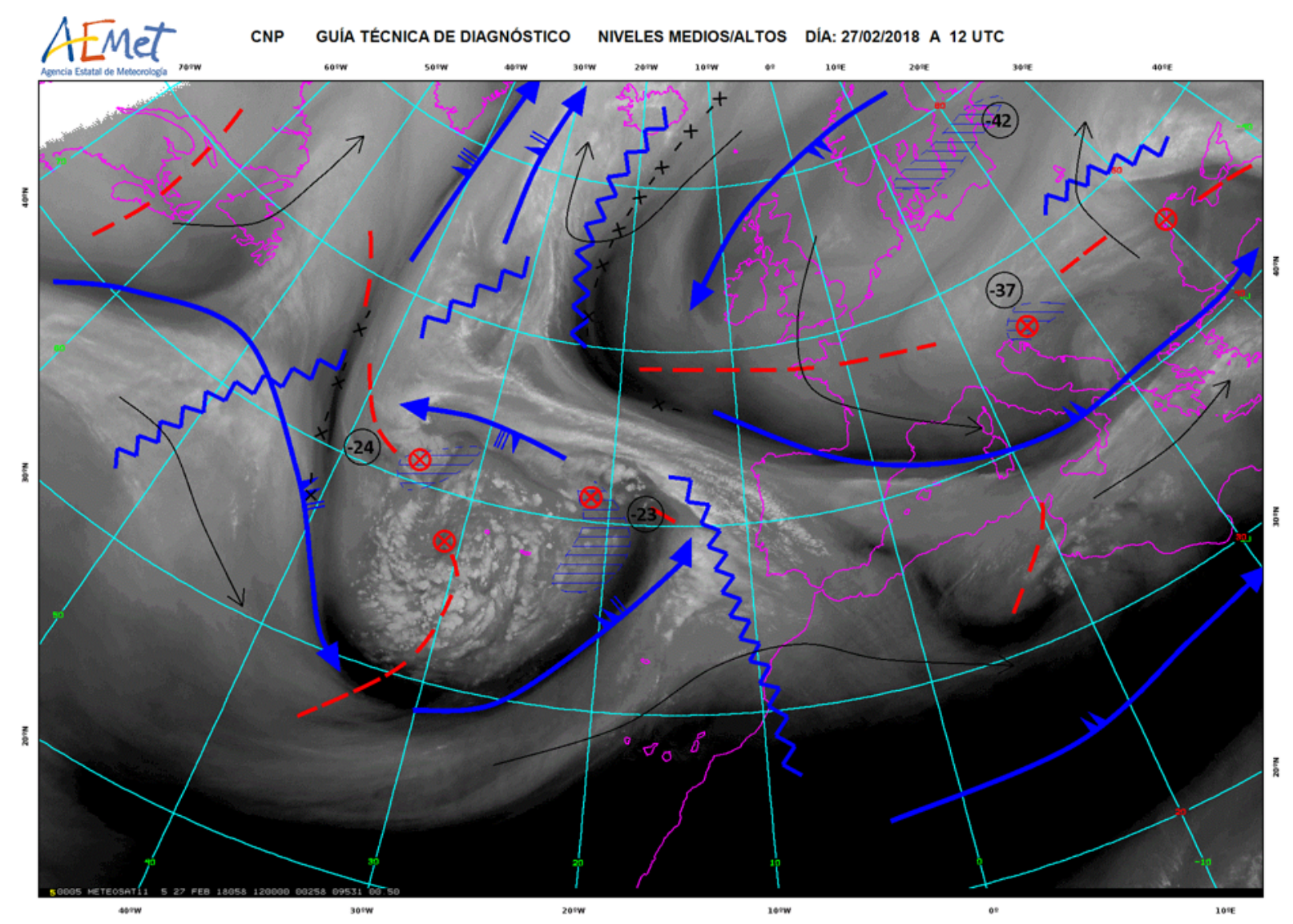

Figura 7.14: Guía técnica de diagnóstico de niveles medios-altos para el día 27-02-2018 a las 12:00 UTC sobre imagen WV 6.2

Las zonas con tonos grises más claros dan información sobre la concentración y la temperatura del vapor de agua en la región que estemos estudiando (dependiendo de la banda utilizada), por ello podemos saber cómo está distribuido el vapor de agua en esas capas de la atmósfera tanto en la horizontal como en la vertical. Además, a través de las secuencias de imágenes, disponibles cada 15 minutos, se puede hacer el seguimiento de su movimiento y evolución. Esto también es muy útil para el cálculo de vientos en las zonas donde no hay nubes.

Teniendo en cuenta que la banda WV 6.2 muestra la distribución tridimensional de humedad en capas altas de la troposfera, permite la identificación de estructuras dinámicas en esos niveles tales como vaguadas, dorsales, bajas, chorros y máximos de viento, zonas de deformación, dobleces de la tropopausa, anomalías de vorticidad potencial, etc.

Por tanto, esta banda WV 6.2 se usa para hacer las guías técnicas de diagnóstico de niveles medios-altos. Tenemos un ejemplo de estas guías en la Figura 7.14 en la que se ve la borrasca Emma en altura, con su centro de vorticidad de curvatura y su nubosidad asociada en altura. Se puede ver un chorro bien definido en la imagen WV 6.2 al sur de la misma y otro al norte de la península ibérica a la altura de los Pirineos.

\subsection{Productos derivados utiliza- dos en predicción operativa}

Además de las imágenes suministradas por las bandas SEVIRI, existe un gran número de composiciones y productos derivados que permiten obtener más información sobre los procesos que están ocurriendo en la atmósfera. Un ejemplo de ello son las imágenes Sandwich, que no son otra cosa que una composición de la banda IR 10.8 con un realce de color a la que se superpone la banda HRVIS. Este producto es muy útil para la vigilancia de sistemas convectivos ya que proporciona las ventajas de ambas bandas a la vez. De esta manera tenemos información sobre la temperatura de los topes nubosos y de su textura de un solo vistazo. 


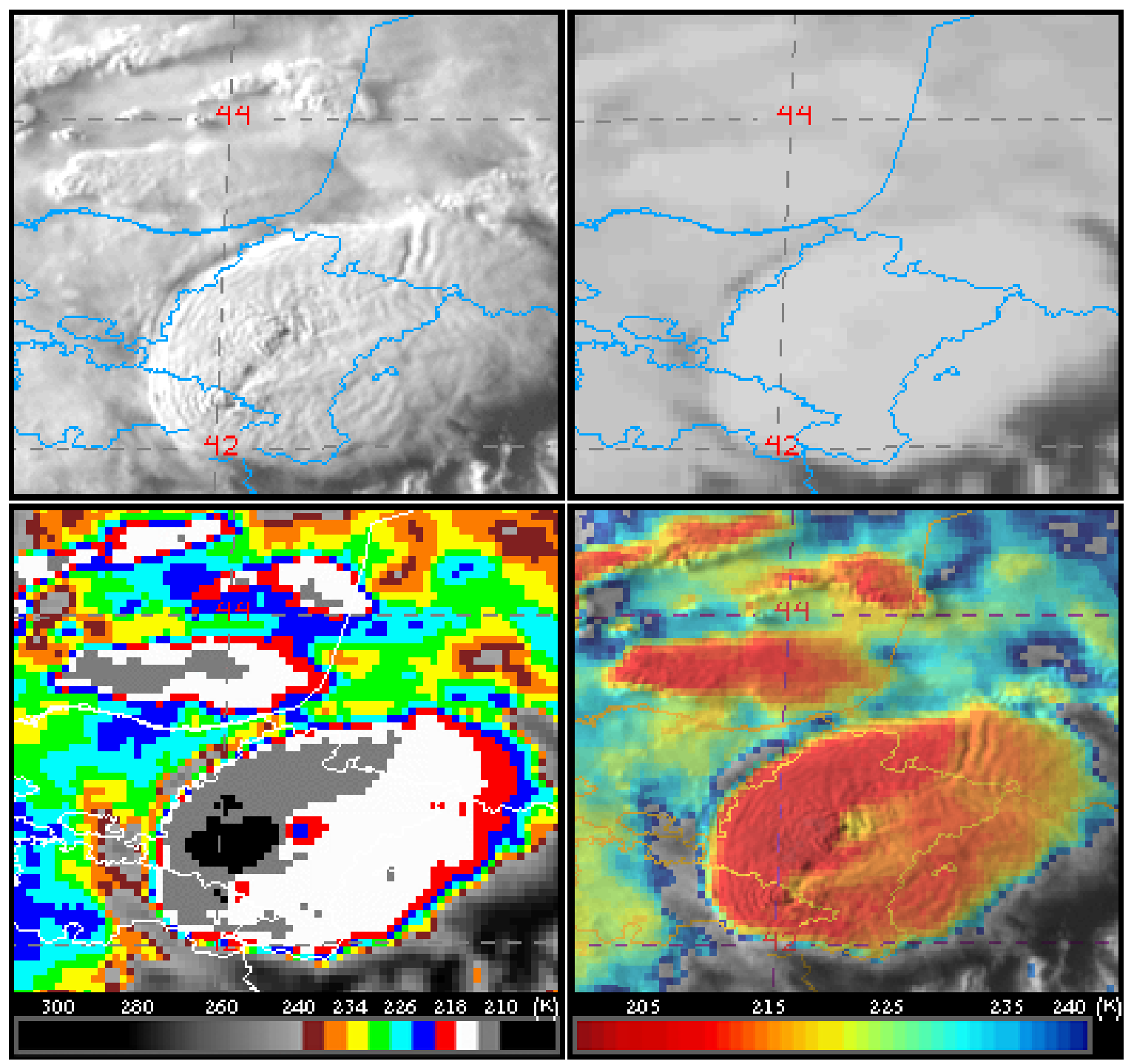

Figura 7.15: Sistema convectivo de mesoescala sobre Navarra ocurrido el 08-06-2017 (imagen de las 18:00 UTC) visto desde el satélite a través de la banda HRVIS (arriba izquierda), banda IR 10.8 sin realce (arriba derecha), banda IR 10.8 con realce PREVIMET (abajo izquierda) y producto Sandwich (abajo derecha).

En la Figura 7.15 se puede ver el tope nuboso de un sistema convectivo de mesoescala (con productos de radar se vio que se trataba de una supercélula). En la imagen que muestra la banda HRVIS se ven varios topes traspasantes sobre el yunque así como las ondulaciones provocadas por los intensos vientos en esa capa.

Si observamos este tipo de estructuras en horas del día en las que el sol no esté demasiado alto, la longitud de las sombras de los topes traspasantes nos puede dar una idea de la severidad del sistema debido a la intensidad de sus corrientes verticales.

En la imagen de la banda IR 10.8 sin realce, sí se puede apreciar la diferencia de resolución horizontal con respecto a la banda HRVIS en este caso, y vemos que por sí misma no proporciona demasiada información ya que los contrastes en la escala de grises no son muy evidentes.

Por esta razón normalmente se aplican realces de color a estas imágenes. Abajo a la izquierda vemos la misma imagen con un realce aplicado (PREVIMET), específico para situaciones de convección. De esta manera podemos apreciar el reflejo del punto cálido a sotavento de dos de los topes traspasantes que detectamos en la banda HRVIS.

La imagen Sandwich, en la que la banda IR 10.8 tiene aplicado un realce de color propuesto por el grupo internacional de convección (Convection Working Group), al que se superpone el canal HRVIS con lo que podemos ver toda la información que hemos obtenido de las anteriores imágenes de una sola vez. 


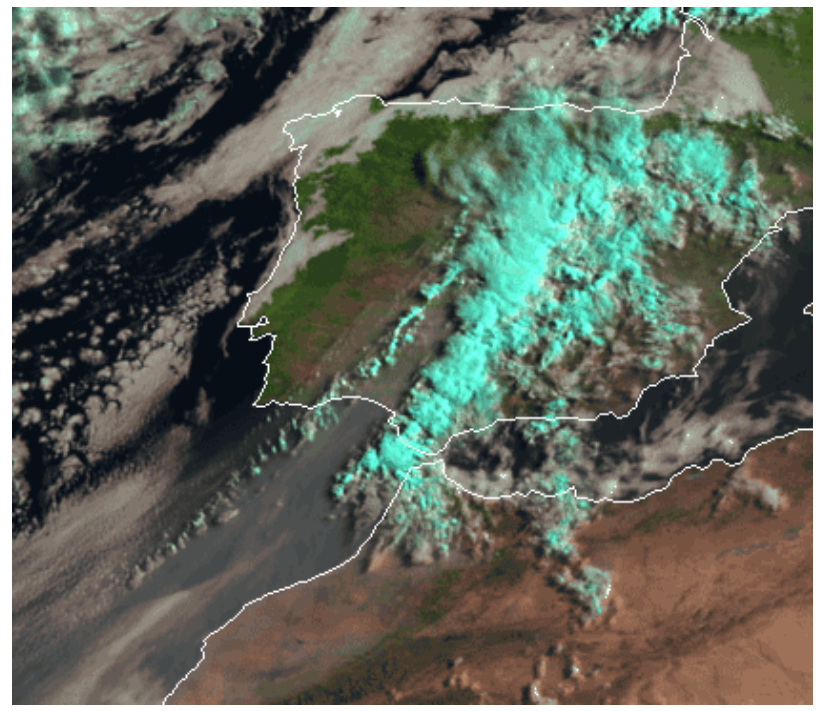

Figura 7.16: RGB Natural del día 20-07-2016 a las 07:00 UTC.

\subsubsection{Composiciones RGB}

Otro tipo de composiciones muy útiles son las imágenes $R G B$. Estas imágenes se basan en la obtención de cualquier color a través de la mezcla por adición de los tres colores primarios de la luz: rojo, verde y azul. De esta forma, construyendo imágenes desde esos tres canales (R,G,B), utilizando en cada canal una banda o diferencia de bandas del satélite, podemos resaltar en diferentes colores las estructuras meteorológicas que nos interesen. Existe ya un gran número de imágenes RGB recomendadas para detectar distinto tipo de situaciones, sin perjuicio de que se puedan obtener otras nuevas con el mismo o distintos objetivos.

Una de las imágenes RGB más utilizadas es la denominada de Color Natural. Ésta consiste en tratar de construir, a partir de las bandas del satélite, una imagen con la misma apariencia que la que vería el ojo humano. Para ello hay que utilizar una banda localizada en el color rojo (618-780 nm) para el canal rojo (R), una banda localizada en el color verde $(497-570 \mathrm{~nm})$ para el canal verde $(G)$ y una banda localizada en el color azul (427-497 nm) para el canal azul (B). De esta manera obtendríamos una imagen en la que la vegetación se vería en colores verdes, el agua azul, la tierra desnuda marrón y las nubes blancas.

En el caso del sensor SEVIRI se utilizan las bandas (NIR 1.6, VIS 0.8, VIS 0.6) que no coinciden exactamente con este esquema, por lo que los colores se ven ligeramente modificados. Lo más llamativo de esta RGB Natural construida a partir de las bandas
SEVIRI es que la nieve y las nubes con topes de hielo se ven en colores turquesa. Esto es debido a que en el canal rojo se introduce la banda NIR 1.6, que refleja poco la radiación en superficies de hielo, con lo cual la ausencia de color rojo produce colores turquesa. No obstante esta imagen RGB Natural es útil para el estudio y evolución de los sistemas nubosos así como la detección de humo y polvo en suspensión sobre el océano, siempre durante el día. Un ejemplo de la misma se puede observar en la Figura 7.16, donde un sistema nuboso con topes de hielo cruza la península ibérica de sur a norte mientras que una nube de polvo, fácilmente detectable sobre el océano Atlántico, entra por el suroeste.

Para la detección de polvo en suspensión existe también una $R G B$ de Polvo que explota la diferencia que hay entre las emisividades del polvo y de la superficie del desierto en las bandas IR 12.0, IR $10.8 \mathrm{e}$ IR 8.7. Esta RGB, que puede ser utilizada durante las 24 horas del día, es muy útil para el seguimiento de la evolución de las tormentas de polvo del desierto sobre tierra. Durante el día se puede complementar con el uso de la RGB Natural e imágenes realzadas de la banda HRVIS para el seguimiento de polvo sobre mar. Las concentraciones de polvo en suspensión se ven en esta imagen en tonos rosa y magenta, tal como muestra Figura 7.17 en la que se ve una tormenta de polvo sobre Mauritania, Malí y el sur de Argelia que tuvo lugar el 17-07-2016. Existe una modificación de esta RGB para la detección de cenizas volcánicas, en las que dichas cenizas se ven en tonos rojos y las nubes de dióxido de azufre se distinguen en verde.

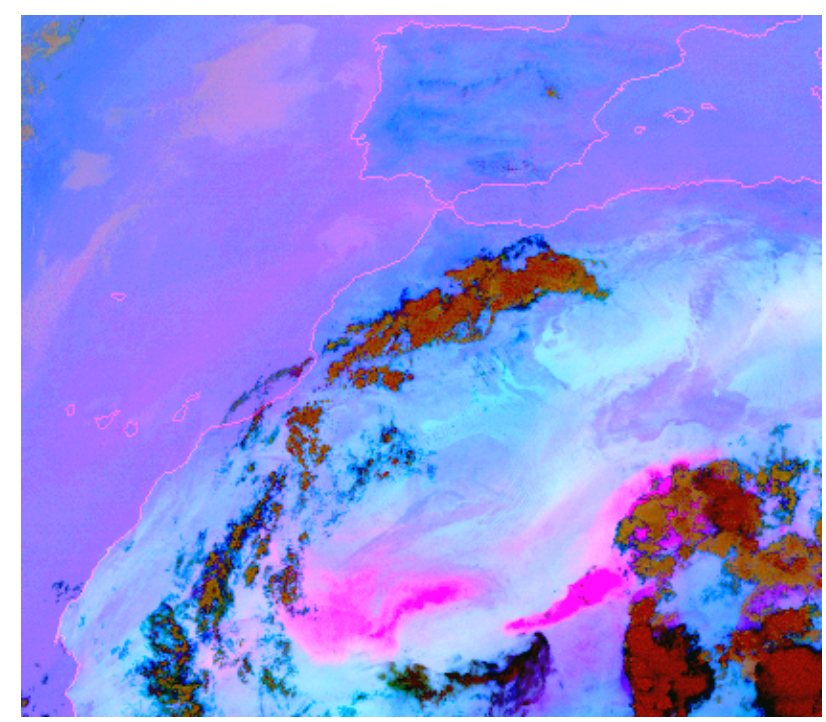

Figura 7.17: RGB de Polvo del día 17-07-2016 a las 18:00 UTC. 


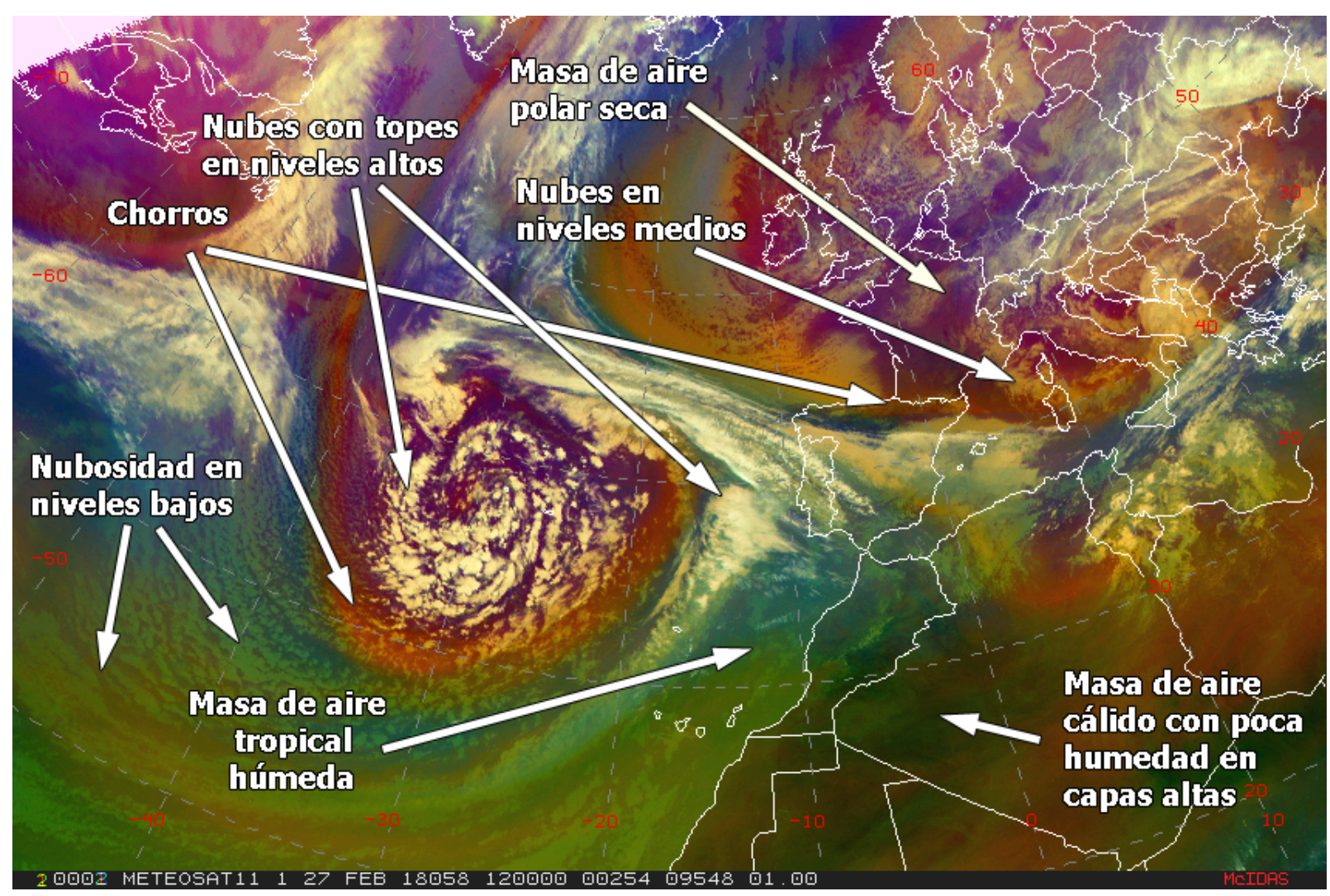

Figura 7.18: RGB de Masas de Aire el 27-02-2018 a las 12:00 UTC.

Una de las RGB más interesantes es la llamada de Masas de Aire. Esta RGB, que puede ser utilizada las 24 horas del día ya que se basa en bandas IR, utiliza las bandas de absorción de vapor de agua y ozono, con lo que centra su atención más en las masas de aire que en las propias nubes, permitiendo distinguir entre masas de aire polar y tropical. También sirve para distinguir nubes en niveles altos de nubes en niveles medios. Las nubes en niveles bajos se distinguen mal con esta RGB. Teniendo en cuenta que con esta RGB se puede hacer un seguimiento de las masas de aire con diferentes características, es muy útil para analizar los procesos dinámicos en la atmósfera, sobretodo en niveles medios y altos. Con ella se puede estudiar la evolución de sistemas de bajas presiones, en particular aquellas con ciclogénesis rápida, detectar la posición de los chorros y zonas de deformación, zonas con anomalías de vorticidad potencial, así como sistemas frontales con el aire seco estratosférico descendiendo en su parte trasera.

Para interpretar esta RGB hay que saber que las zonas azuladas se refieren a aire polar frío con alto contenido en ozono. Las masas de aire en colores verde claro son aire tropical, cálido, con bajo contenido en ozono y humedad en capas altas. Si el verde es oscuro, tirando a marrón, la masa de aire es cálida pero con bajo contenido en humedad en capas altas. Y las zonas rojizas se refieren a aire seco, pudiendo ser zonas de subsidencia, chorros o anomalías de vorticidad potencial. En cuanto a nubes se refiere, aquellas espesas con topes en niveles altos, se ven blancas. Si son nubes en niveles medios se ven color marrón claro o dorado. Las nubes bajas no se distinguen bien, salvo por su estructura, ya que toman el color de la masa de aire en las que están inmersas.

En la Figura 7.18 se ve la RGB de Masas de Aire para la situación del 27-02-2018 a las 12:00 UTC, en la que se ve la borrasca Emma en el Atlántico y dos masas de aire, una polar, fría y seca, y una tropical más cálida y cargada de humedad, chocando sobre la península ibérica.

Existen otras RGBs muy útiles como la de Nieblas y nubes bajas de noche, que se basa en las diferentes capacidades de absorción que tienen el agua y el hielo en los distintos canales IR de SEVIRI. Esta RGB, que solo funciona por la noche, muestra los estratos bajos y las nieblas, es decir, las nubes formadas por gotitas de agua líquida, en colores verde claro, que contrastan claramente con la superficie de la tierra en colores rosados y del mar en colores lilas, y con el resto de nubes en colores rojos y anaranjados. 
Otra RGB muy popular es la específica para Convección. Esta RGB se utiliza en la caracterización de nubes convectivas, al ser útil para diferenciar la altura de las nubes, la fase y el tamaño de las partículas que se encuentran en sus topes. Las nubes con convección profunda aparecen en color amarillo y naranja intenso. La diferencia está en que las nubes con corrientes ascendentes intensas con cristales de hielo pequeños en sus topes, es decir, nubes convectivas en estado de crecimiento y muy activas, aparecen en color amari1lo. Aquellas nubes convectivas con cristales de hielo grandes en sus topes, en fase de disipación, se ven anaranjadas. Esto permite diferenciar el estado de evolución del sistema convectivo que se está vigilando.

\subsubsection{Productos del NWCSAF}

Además de las composiciones tipo RGB, existen a disposición del predictor un gran número de productos derivados, que no solo utilizan información de las bandas del satélite, sino que compilan otro tipo de información, como puede ser datos de rayos o campos de modelos numéricos, para hacer estimaciones de un gran número de variables. En este sentido y, para una mejor explotación de los datos de satélite, EUMETSAT ha impulsado la creación de ocho centros de excelencia dedicados a explotar los datos de satélite en diferentes ámbitos, como puede ser clima, hidrología, composición atmosférica, etc. El primero en formarse fue el dedicado al nowcasting, que está liderado por AEMET y en el que también participan los Servicios Meteorológicos Nacionales de Francia, Suecia, Austria y Rumanía. Este consorcio, denominado NWCSAF (Satellite Application Facility in support to Nowcasting and Very Short Range Forecasting), se dedica a desarrollar productos útiles en las tareas de nowcasting y vigilancia de sistemas convectivos.

En el paquete de software que distribuye el NWC$\mathrm{SAF}$ se pueden encontrar productos de nubes, tales como una máscara nubosa (Cloud Mask - CMa), un producto que informa sobre el tipo de nube (Cloud Type - CT) diferenciando entre nubes espesas con topes en niveles bajos, medios, altos y muy altos, y nubes fraccionales y semitransparentes. También existe un producto que proporciona información sobre la altura, la temperatura y la presión de los topes nubosos (Cloud Top Temperature and Height - CTTH), muy útil para aplicaciones aeronáuticas.

Unos productos especialmente interesantes que podemos encontrar en el paquete de software del NWC-
SAF son los productos de aire claro (imagery Satellite Humidity and Instability - iSHAI). Estos productos, que solo se calculan en las zonas donde no hay nube, parten de perfiles verticales de humedad y temperatura (también los perfiles de contenido de ozono de manera opcional) dados por un modelo numérico, y utilizando la información contenida en las bandas de SEVIRI, se corrigen conforme a la observación. En AEMET se utilizan los campos del ECHRES. A partir de los perfiles corregidos se calculan campos de agua precipitable en tres capas:

- BL (boundary layer) entre la superficie y $850 \mathrm{hPa}$.

- ML (medium layer) entre 850 y $500 \mathrm{hPa}$.

- HL (high layer) entre $500 \mathrm{hPa}$ y el tope de la atmósfera.

Asimismo, se calcula el agua precipitable total en la columna (TWP). También se calculan los índices de inestabilidad Lifted Index, K-Index y Showalter (sec. 6.2.5 en la página 75). El campo de temperatura de skin (ver caja más adelante), y de manera opcional, en caso de que haya sido introducido como entrada en el producto, los perfiles verticales de contenido de ozono, corregidos.

Skin temperature es la temperatura de una capa de espesor infinitesimal sobre una superficie de tierra o agua que se encuentra en equilibrio radiativo (https://software.ecmwf.int/wiki/ display/UER/Skin+temperature).

Teniendo en cuenta que estos productos se calculan en zonas donde todavía no se han empezado a formar nubes, permiten una estimación previa a la aparición de las primeras nubes de las regiones críticas donde se pueden esperar desarrollos convectivos, ya que proporcionan información sobre dos de los tres ingredientes necesarios para que se inicie la convección (humedad e inestabilidad).

Además de los mencionados campos de humedad e índices de inestabilidad, el producto proporciona información sobre la magnitud de las correcciones realizadas, es decir, muestra campos de diferencia para cada parámetro (campos del producto menos campos del modelo sin corregir). Esta información puede ser muy útil para el predictor en el sentido de que le permite evaluar el comportamiento del modelo en el momento en el que hay observaciones y extrapolar la información obtenida a momentos futuros. 


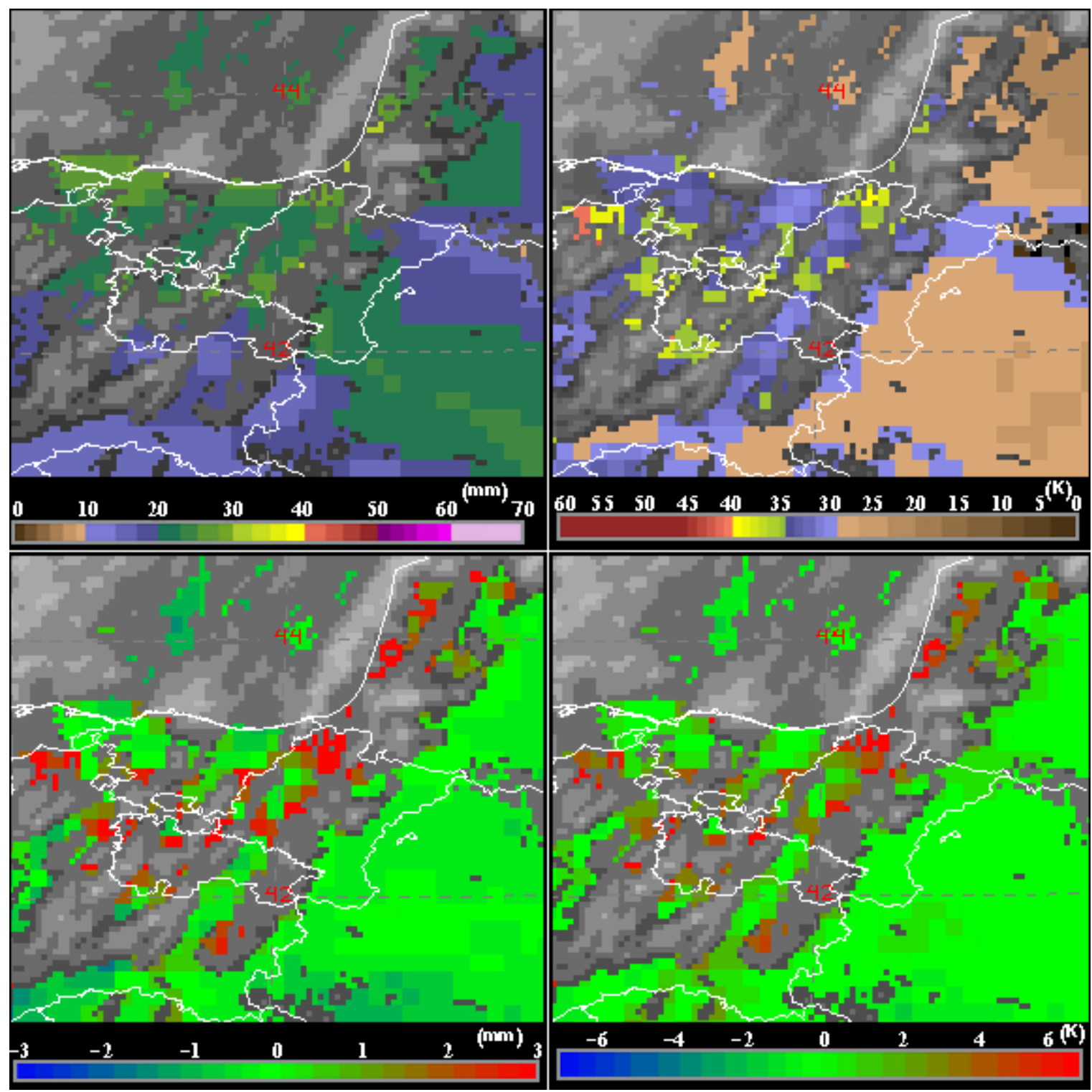

Figura 7.19: Campos de total de agua precipitable (arriba izquierda), diferencia del campo del total de agua precipitable con el modelo (abajo izquierda), índice $K$ (arriba derecha) y diferencia del índice $K$ con el modelo (abajo derecha) del producto iSHAI del NWCSAF (NWCSAF (C) 2016 EUMETSAT), para la situación del día 08-06-2017 a las 11:00 UTC.

En la Figura 7.19 vemos un ejemplo de los campos del total de agua precipitable y del índice $\mathrm{K}$ junto con sus campos de diferencia con el modelo para el día 08-06-2017 a las 11:00 UTC. Se trata de la misma situación que el sistema convectivo mostrado en la Figura 7.15 en la página 95 vista unas horas antes. A través de estas imágenes se aprecia que la masa de aire, que de por sí es húmeda, contiene más humedad que la pronosticada por el modelo. También muestra, a través del índice $\mathrm{K}$ que la probabilidad de ocurrencia de tormentas es superior al $80 \%$ en algunos puntos, donde también está infra estimada por el modelo.

Productos interesantes para la vigilancia incluidos en el paquete del NWCSAF son, por ejemplo, el pro- ducto de vientos (High Resolution Winds - HRW), que a través de trazadores encontrados en los topes nubosos, en los bordes de las nubes o en zonas características de las imágenes de vapor de agua, y a través de comparación de los mismos en imágenes sucesivas, calcula vientos de alta resolución (intensidad, dirección y trayectoria). La información proporcionada por este producto puede ser útil para la vigilancia de situaciones con vientos fuertes, para el estudio del flujo general, para buscar zonas de convergencia y divergencia en distintos niveles, así como para el estudio de circulaciones a pequeña escala.

También hay productos específicos para la precipitación. Uno que proporciona información sobre la 
probabilidad de que una nube dada produzca precipitación (Precipitating Clouds - PC) y otro para la estimación de precipitación convectiva en superficie a partir de las características de los topes nubosos (Convective Rainfall Rate - CRR), útiles sobre todo en las zonas donde el radar meteorológico no está disponible o como complemento del mismo. Ambos productos se calculan a su vez a través de dos algoritmos diferentes. Uno de ellos utiliza directamente las radiancias de los topes nubosos, lo que provoca que los patrones de precipitación tengan una forma parecida a dichos topes nubosos, sobrestimando normalmente las áreas de precipitación e infraestimando las intensidades. El otro tipo de algoritmo se basa en las propiedades microfísicas de los topes nubosos, que han demostrado estar mejor correlacionadas con la precipitación que las radiancias, por ello este algoritmo muestra unas estimaciones mejor ajustadas a las detectadas por el radar. La limitación que muestran estos productos que utilizan las propiedades microfísicas de los topes nubosos es que solo están disponibles durante el día, de ahí la duplicidad de los productos.

Específico para la vigilancia de sistemas convectivos es el producto de tormentas en desarrollo rápido (Rapid Developing Thunderstorms - RDT) que hace una detección de células convectivas basándose en umbrales adaptativos de temperatura de brillo de la banda IR 10.8, y su seguimiento en imágenes consecutivas. En la visualización disponible para los predictores de AEMET, muestra las células convectivas a través de su contorno, proporcionando además información sobre su estado de evolución. También dibuja la trayectoria del centroide correspondiente a cada célula hasta el momento de captura de la imagen y su trayectoria prevista. En la Figura 7.20 se pueden ver las células convectivas detectadas por este producto sobre el sur de España el día 01-03-2018 a las 13:00 UTC.

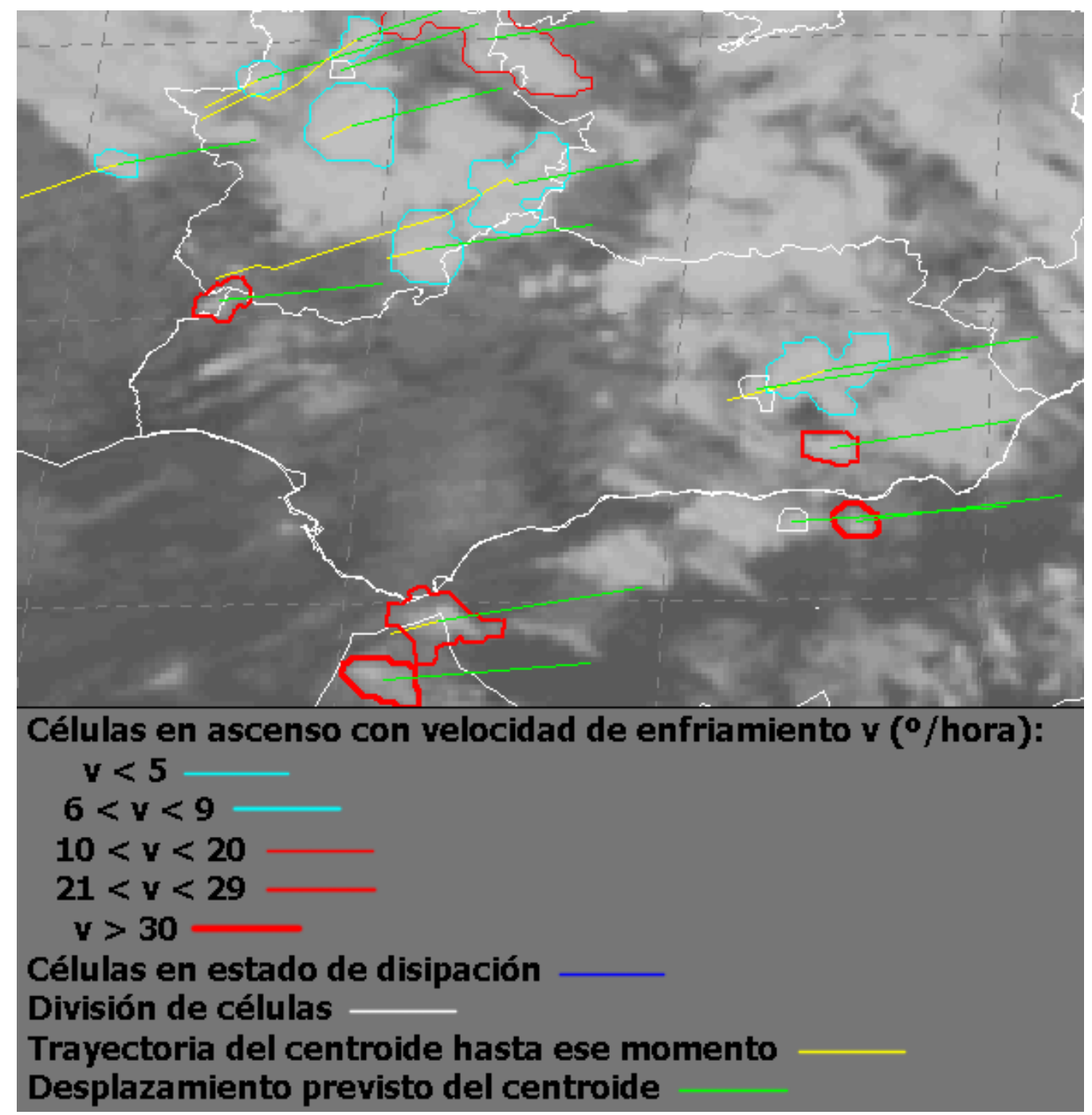

Figura 7.20: Producto de tormentas en desarrollo rápido del NWCSAF (NWCSAF @ 2016 EUMETSAT) el día 01-03-2018 a las 13:00 UTC. 
En la última versión del paquete de software del NWCSAF se han incluido algunos productos en estado de pruebas que parecen bastante prometedores. Entre ellos se encuentran:

- Producto ASII-NG (Automatic Satellite Image Interpretation-Next Generation) dedicado a la detección de turbulencia en aire claro debido a dobleces de la tropopausa. Producto muy útil en la predicción aeronáutica.

- Producto de inicio de la convección CI (Convection Initiation) que da la probabilidad de que un pixel nuboso se convierta en una tormenta en un periodo de tiempo dado. Este producto pretende captar los primeros estados del inicio de la convección, cuando aparecen los primeros indicios después de la formación de las primeras nubes o con la modificación de las condiciones medioambientales. Esta información es de gran interés para las tareas de nowcasting y vigilancia.

- Producto de extrapolación temporal de imágenes EXIM (Extrapolated Imagery Processor), que hace una extrapolación cinemática utilizando los vectores de movimiento calculados por el producto HRW de los productos CMa, CT, CTTH (campos de presión y altura) y CRR, con alcance de hasta una hora.

\subsection{Misiones futuras}

Actualmente ya se encuentra operativo el último satélite de la serie MSG, el MSG-4. Por ello EUMETSAT, en colaboración con la Agencia Espacial Europea (ESA), ya tiene previsto el lanzamiento de la siguiente serie de satélites geostacionarios, los Meteosat de Tercera Generación (MTG).

A diferencia de las series anteriores, esta serie incluirá dos tipos de satélite diferentes, uno centrado en sensores de imagen (MTG-I) y otro que llevará instrumentos sondeadores a bordo (MTG-S).

El primero de los instrumentos que irán embarcados a bordo de los satélites MTG-I será un radiómetro de imagen (Flexible Combined Imager - FCI), que funcionará como continuación del sensor SEVIRI a bordo de MSG. Este radiómetro tomará medidas en 16 bandas, ocho de las cuales estarán situadas en la región solar del espectro, entre 0.4 y $2.2 \mu \mathrm{m}$, con resolución horizontal en nadir de $1 \mathrm{~km}$. Las restantes ocho bandas tomarán medidas en el rango del IR térmico entre 3.8 y $13.4 \mu \mathrm{m}$, con resolución horizontal de $2 \mathrm{~km}$ en nadir. La resolución temporal será de 10 minutos en el modo de escaneo de disco completo (Full Disk Scan - FDS). En el modo de escaneo rápido (Rapid Scan - RSS), el radiómetro FCI escaneará una cuarta parte del disco sobre Europa, con una resolución temporal de 2.5 minutos y proporcionando una resolución espacial de $0.5 \mathrm{~km}$ para las bandas VIS 0.6 y NIR 2.2, y de $1 \mathrm{~km}$ para las bandas IR 3.8 e IR 10.5 .

El instrumento novedoso que irá embarcado en los satélites MTG-I será un detector de rayos en tiempo real (Lightning Imager - LI) que detectará rayos nubenube y nube-tierra e informará sobre su localización con una resolución espacial de $4.5 \mathrm{~km}$.

A bordo del satélite MTG-S irán embarcados dos sondeadores:

- Sondeador IR (Infrared Sounder - IRS) que tomará medidas en dos regiones del espectro con intervalo de muestreo espectral de $0.625 \mathrm{~cm}^{-1}: 1600 \mathrm{a}$ $2250 \mathrm{~cm}^{-1}(4.44-6.25 \mu \mathrm{m})$ y 680 a $1210 \mathrm{~cm}^{-1}$ $(8.26-14.70 \mu \mathrm{m})$. Su resolución espacial será de $4 \mathrm{~km}$ en nadir y tomará medidas del disco completo cada hora. Este sensor proporcionará información detallada de los perfiles verticales de temperatura y humedad, suponiendo una mejora importante para los productos de aire claro.

- Sondeador en las regiones ultravioleta, visible e IR cercano del espectro (Ultra-violet, Visible and Nearinfrared Sounder - UVN), diseñado para el estudio de la química atmosférica. Es un espectrómetro que toma medidas en tres regiones del espectro: UV: 305-400 nm, visible: $400-500 \mathrm{~nm}$ e IR cercano: 755-775 nm, con una resolución espacial menor que $10 \mathrm{~km}$ y una resolución temporal menor o igual que una hora en un área entre $30^{\circ}$ y $65^{\circ} \mathrm{N}$ en latitud y $30^{\circ} \mathrm{O}$ a $45^{\circ} \mathrm{E}$ en longitud.

La serie de satélites MTG constará de cuatro satélites MTG-I, el primero de los cuales está planificado ser lanzado a finales de 2021, y dos MTG-S, el primero de los cuales está planificado ser lanzado a comienzos de 2023. Esta misión se prevé que trabaje a capacidad completa con la utilización a la vez de un satélite MTG-S y dos MTG-I, uno dedicado al escaneo del disco completo y otro dedicado al servicio de escaneo rápido, tal como se muestra en la Figura 7.21 en la página siguiente. 


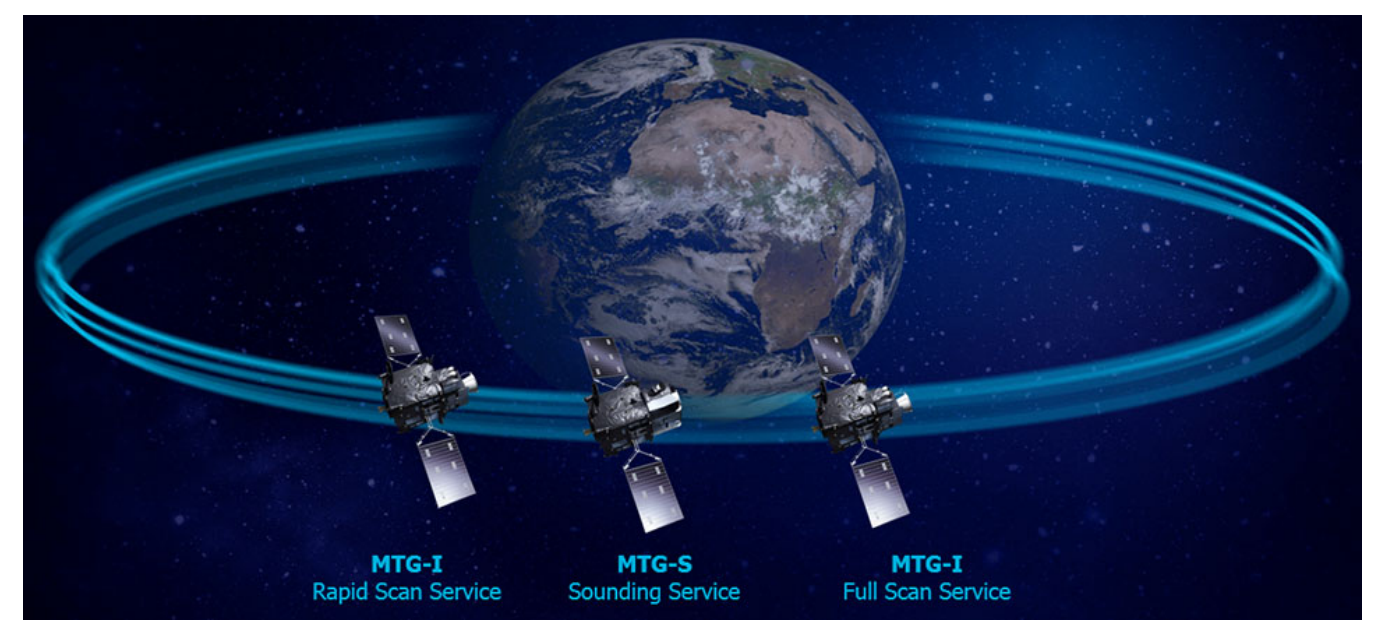

Figura 7.21: Constelación completa de los satélites Meteosat de Tercera Generación. Fuente: EUMETSAT.

\subsection{Enlaces de interés}

- https://www.nasa.gov/centers/goddard/missions/ats.html

- https://www.nasa.gov/content/goes-overview/index.html

- https://www. eumetsat.int

- https://pmm.nasa.gov/trmm/trmm-instruments

- https://www.nasa.gov/mission_pages/GPM/spacecraft/index.html

- http://eumetrain.org/satmanu/index.html\#here

- https://www.meted.ucar.edu/training_module.php?id=1108\#.WbeJ7bKrTCM

- http://tropic.ssec.wisc.edu/real-time/mtpw2/about.html 


\subsection{Referencias}

[1] BADER, M J y col. Images of weather forecasting: A practical guide for interpreting satellite and radar imagery. Cambridge University Press, 1995 (citado en página 88).

[2] BRowning, K A y col. "Application of satellite imagery in newcasting and very short range forecasting". En: Meteorological Magazine 116.1379 (1987), páginas 161-179 (citado en páginas 84,91 ).

[3] EzELL, Linda Neuman. "NASA historical data book. Volume 3: Programs and projects 1969-1978”. En: (1988) (citado en página 86).

[4] Georgiev, Christo, Santurette, Patrick y MAYNARD, Karine. Weather analysis and forecasting: applying satellite water vapor imagery and potential vorticity analysis. Academic Press, 2016 (citado en página 92).

[5] KelKar, R R. Satellite meteorology. BS Publications, 2007 (citado en página 84).

[6] Kidder, Stanley Q y HAAR, Thomas H Vonder. Satellite meteorology: an introduction. Gulf Professional Publishing, 1995 (citado en página 84).

[7] Liou, Kuo-Nan. An introduction to atmospheric radiation. Volumen 84. Elsevier, 2002 (citado en páginas $84,85,88$ ).

[8] Menzel, W Paul y Satellite, NOAA. "Remote sensing applications with meteorological satellites". En: The Solar Spectrum 3 (2005), página 10 (citado en páginas 87, 90). 